\title{
WLIN iv
}

\section{U. S. ATOMIC ENERGY COMMISSION}

RAW MATERIALS DEVELOPMENT LABORATORY WINCHESTER, MASSACHUSETTS

\section{OPERATED BY \\ NATIONAL LEAD COMPANY, INC.}

Contract AT(49-6)-924

\section{AEC RESEARCH AND DEVELOPMENT REPORT}

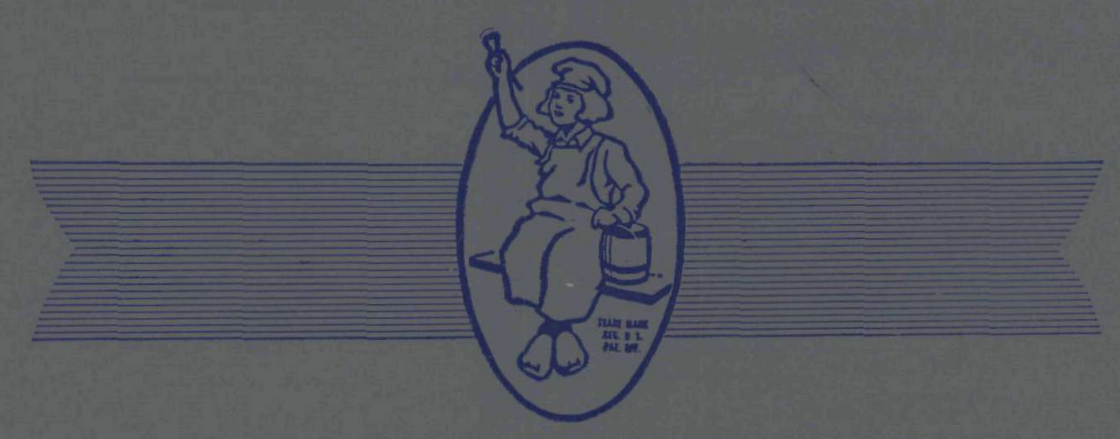


This report was prepared as an account of Government sponsored work. Neither the United States, nor the Commission, nor any person acting on behalf of the Commission:

A. Makes any warranty or representation, express or implied, with respect to the accuracy, completeness, or usefulness of the information contained in this report, or that the use of any information, apparatus, method, or process disclosed in this report may not infringe privately owned rights; or

B. Assumes any liabilities with respect to the use of, or for damages resulting from the use of any information, apparatus, method, or process disclosed in this report.

As used in the above, "person acting on behalf of the Commission" includes any employee or contractor of the Commission to the extent that such employee or contractor prepares, handles or distributes, or provides access to, any information pursuant to his employment or contract with the Commission. 
TOPICAL REPORT WIN-90

PREPARATION OF DENSE, METAI_GRADE UE 4 FROM

ORES AND CONCENTRATES 


\section{DISCLAIMER}

This report was prepared as an account of work sponsored by an agency of the United States Government. Neither the United States Government nor any agency Thereof, nor any of their employees, makes any warranty, express or implied, or assumes any legal liability or responsibility for the accuracy, completeness, or usefulness of any information, apparatus, product, or process disclosed, or represents that its use would not infringe privately owned rights. Reference herein to any specific commercial product, process, or service by trade name, trademark, manufacturer, or otherwise does not necessarily constitute or imply its endorsement, recommendation, or favoring by the United States Government or any agency thereof. The views and opinions of authors expressed herein do not necessarily state or reflect those of the United States Government or any agency thereof. 


\section{DISCLAIMER}

Portions of this document may be illegible in electronic image products. Images are produced from the best available original document. 
WIN -90

Metallurgy. - Raw Materials

M-3679 - (21th Edition)

-1 -

TOPICAL REPORT WIN-90

RREPARATION OF DENSE, METAL_GRADE UE, FROM ORES AND CONCENTRATES

By

H. G. Petrow, R. J. Allen, and P. J. Magno

May 15, 1958

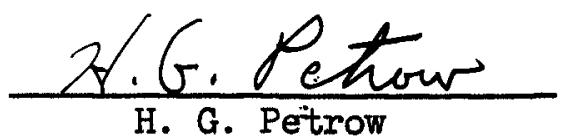

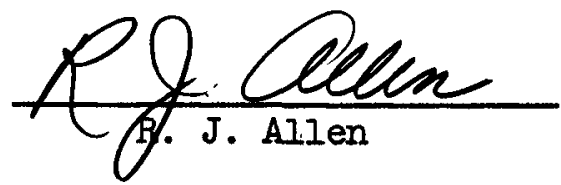

$\frac{\text { P. J. Magno }}{\text { P. J. Magno }}$
Approved by $\frac{M \cdot a \cdot \text { De teara }}{\text { M. A. DeSesa }}$

Head, Chemical Department

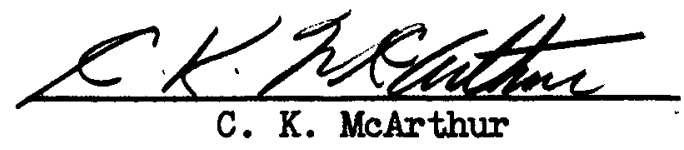

Technical Director

U. S. Atomic Energy Commission Contract No. AT $(49-6)-924$

National Iead Company, Inc. Raw Materials Development Laboratory

Winchester, Massachusetts 
Internal Distribution

G. W. Wunder 
WIN-90

-2 -

\section{ABSTRACT}

A process for the preparation of dense, metal-grade $\mathrm{UF}_{4}$ from ores and concentrates is described. 
TABIE OF CONTENTS

Page

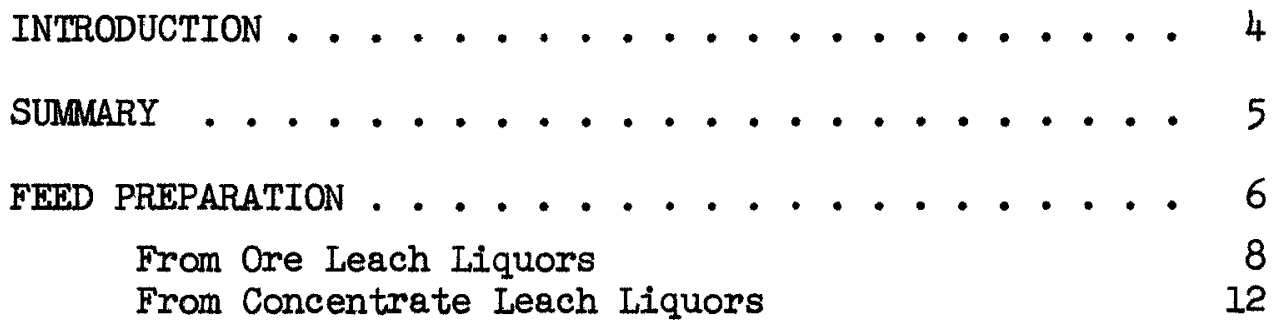

PRECIPITATION OF URANIUM TETRAFLUORIDE BY THE CATALYTIC REDUCTION PROCESS . . . . . . . . . . . . 14

Screening of Chemical Reducing Agents 16

Solid Reductants 17

Water Soluble Reductants 17

Catalytic Reduction Systems 18

Equipment and Experimental Procedures 20

Recovery with Increasing Uranium Concentration 21

Reaction Temperature 22

Stirring as a Variable 23

Larger Scale Production of $\mathrm{UF}_{4} \cdot 3 / 4 \mathrm{H}_{2} \mathrm{O} \quad 24$

Physical Properties of Prepared Green Salt 25

Preparation of Other Uranium(IV) Salts 27

Precipitation from Solutions Other Than Hydrochloric

Acid Strip Solutions $\quad 27$

VARIABLES INVOLVED IN THE PRECIPITATION OF UF 4 BY THE

CATALYTIC REDUCTION PROCESS ........... 28

Reduction of Cupric Copper by Sulfur Dioxide 31

Reduction of Uranyl Ion by Cuprous Chloride 32

LITERATURE CITED . . . . . . . . . . . . 33

TABIES . . . . . . . . . . . 35

FIGURES . . . . . . . . . . . . . 41 
WIN-90

-4 -

\section{INTRODUCTION}

The preparation of dense, high-purity $\mathrm{UF}_{4}$ (green salt) by a wet chemical technique has been the subject of investigations in several laboratories.1-9 Both sulfuric acid leach liquors and uranium concentrates have been considered as possible feed materials for the proposed green salt processes. The processes thus far presented have been gravely handicapped for several reasons including cost, product purity, product density, and process simplicity. With these considerations in mind, this laboratory commenced research on a process designed to produce dense, high-purity $\mathrm{UF}_{4}$ from either a sulfuric acid leach liquor or a uranium concentrate. The underlying philosophy of the research program has been to produce, if possible, a continuous process of maximum simplicity and low capital and chemical costs.

The research program was divided into two major categories, the preparation of an adequate feed material, and the discovery of a suitable uranium reduction-precipitation technique. Both of these goals have been achieved, and an integrated flow sheet for the preparation of $\mathrm{UF}_{4}$ by $a$ wet chemical process has been developed. 
WIN-90

\section{SUMMARY}

Commencing with a sulfuric acid solution of uranium prepared from either ore or concentrate, the uranium is solvent extracted into a kerosene solution of an amine. The uranium is stripped from the solvent into hydrochloric acid.

Hydrofluoric acid and cupric sulfate are added to the pregnant strip solution and $\mathrm{UF}_{4}$ precipitated by bubbling $\mathrm{SO}_{2}$ through the hot solution. Copper acts as a catalyst for the reduction of uranium. The $\mathrm{UF}_{4}$ prepared by this technique meets metal grade purity specifications and has a tap density in excess of $3.0^{\circ}$ grams per milliliter. 


\section{FEED PREPARATION}

If pure $\mathrm{UF}_{4}$ is to be precipitated from aqueous solution, a careful separation of uranium from many inorganic ions must be effected. All ions, or combinations of ions, forming insoluble fluorides, or uranium(IV) salts of solubility comparable to $\mathrm{UF}_{4}$ must be absent from the solution. Also, alkali metal ions must be absent or present in low concentrations since they form insoluble double fluorides with uranium(IV).

Uranium can be efficiently recovered from sulfate solution by either ion exchange or solvent extraction. This laboratory chose to concentrate on solvent extraction techniques, specifically with long chain secondary and tertiary amines, largely because of the flexibility, simplicity, and selectivity of solvent extraction techniques when using an amine extractant.

The use of amines as uranium extractants has been intensively studied by several laboratories.10-15 Long chain amines, both secondary and tertiary, are characterized by a selectivity for uranium, high extraction coefficients, and good chemical stability. Uranium recovery costs are low. Because of the ease with which uranium can be re-extracted from the organic phase with a chloride solution, the amine extractants offer an excellent means of preparing concentrated solutions of uranium containing virtually no extraneous inorganic material other than chloride, sulfate, and hydrogen ions.

The selectivity with which amines extract uranium from sulfuric acid leach liquors is well known. Neither secondary nor tertiary amines will extract alkali, alkaline earth or trivalent rare earth ions, nickel(II), cobalt(II), aluminum (III), iron(II), vanadium(IV), cadmium(II), copper(I, II), silver(I), chromium(III), lead(II), manganese(II), zinc(II), or boron(III). Both secondary and tertiary amines will extract partially or completely zirconium(IV), presumably hafnium(IV), cerium(IV), titanium(IV), vanadium(V), and molybdenum(VI). Secondary amines will extract small amounts of iron(III) and thorium(IV), whereas tertiary amines will extract, at the most, only traces of these latter two elements. 
Of the anions likely to be present in a leach liquor, the amines will extract small quantities of phosphate and arsenic. This is more pronounced with secondary amines than with tertiary amines. Phosphate is objectionable since it forms an insoluble uranium(IV) salt in acid solutions. This is not true of uranium(IV) and arsenic.

On the basis of known information concerning amine extractants, zirconium(IV), hafnium(IV), titanium(IV), molybdenum(VI), phosphate, and arsenic are potential contaminants of the green salt product. Cerium(IV) and vanadium(V) are of no concern since they are easily reduced to non-extractable species. The extent to which the possible contaminants actually interfere with the production of high-grade green salt is discussed in a later section of this report. However, with most leach liquors and concentrates, molybdenum and phosphate are the only substances commonly encountered at levels high enough to present serious problems.

Several solvent extraction flow sheets have been prepared utilizing amine extractants. These are listed below.

1. Ore leach liquor - Secondary amine - 2M HCI strip.

2. Ore leach liquor - Tertiary amine - 2M HCl strip.

3. Ore leach Iiquor - Tertiary amine - 3M HCl strip.

4. Concentrate leach liquor - Secondary amine - $2 \mathrm{M} H C l$ strip.

5. Concentrate leach liquor - Tertiary amine - 2M HCl strip.

6. Concentrate leach liquor - Tertiary amine - $2 \mathrm{M} \mathrm{HCl}$ strip.

The choice of flow sheet is largely dictated by circumstances such as the chemical constituents in the leach liquor. Secondary amines are at a disadvantage since they are somewhat less selective than tertiary amines. On the other hand secondary amines are easier to strip with hydrochloric acid than are the tertiary amines. However, as will be pointed out later, by an adjustment of the stripping technique, effective stripping of tertiary amines with hydrochloric acid is possible and with an efficiency almost as high as is attainable with secondary amines. 


\section{Erom Ore Ieach Eiquors}

The solvent extraction of uranium from sulfate systems is well documented and need not be discussed here. The overall flow sheet for the extraction of uranium from a leach liquor by a secondary amine and subsequent stripping with $2 \mathrm{M} \mathrm{HCl}$ is presented in Figure 1. Four stages of extraction are followed by a single scrub stage. The scrubbing solution is $0.5 \mathrm{M} \mathrm{H}_{2} \mathrm{SO}_{4}$. The organic to scrub ratio is maintained at about 10 to 1 . About 1 per cent of the uranium reports to the scrubbing solution and this uranium, along with the acid, is recycled to the leach circuit. The purpose of the scrub is twofold. First, small quantities of leach liquor entrained in the pregnant organic are a potential source of contamination. The scrub serves to remove this material. Secondly, the scrub circuit also removes phosphate extracted into the solvent and thereby prevents the phosphate from being precipitated later, along with the UF 4 .

After being scrubbed, the pregnant organic is stripped in three or four stages with $2 \mathrm{M} \mathrm{HCl}$. Depending upon the secondary amine used, pregnant solutions averaging 70 to 100 grams $\mathrm{U}_{3} \mathrm{O}_{8}$ per liter are obtained. The stripped organic is recycled to the extraction circult. If the quantity of molybdenum present in the leach liquor is low, its presence can be ignored. However, if the concentration is high, periodic carbonate scrubbing of the stripped organic will be necessary in order to prevent the molybdenum concentration from building up in the organic phase. The carbonate scrub circuit is not indicated in the flow sheet of Figure 1.

The flow sheet of Figure 1 has been tested with two secondary amines and shown to give pure, concentrated uranium solutions with ferric iron and small quantities of molybdenum being the principal impurities. Using either Rohm \& Haas Amine 9D-178 or Union Carbide Amine S-24, pregnant solutions assaying 70 to 100 grams $\mathrm{U}_{3} \mathrm{O}_{8}$ per liter, 100 grams $\mathrm{SO}_{4}=$ per liter, 17 grams $\mathrm{Cl}^{-}$per 11 ter, 1 gram $\mathrm{Fe}^{+++}$per liter, and 0.05 grams Mo per liter were obtained. Both amines were 5 per cent v/v solutions in kerosene containing 2.5 volume per cent primary decyl alcohol (PDA).

The flow sheet of Figure 1 was also tested using General Mills Alamine, a $C_{8}-C_{10}$ trifatty amine. It was found, however, that it was not possible to get complete uranium 
stripping with $2 \mathrm{M} \mathrm{HCl}$ due to the extraction of a uranyl chloride complex ion. For this reason, the flow sheet had to be modified in order to allow the use of a tertlary amine, since other tertiary amines such as trilsooctylamine, also behaved in a manner similar to Alamine.

A $0.1 M$ solution of Alamine in kerosene containing 5 volume per cent PDA was saturated with uranium from a sulfuric acid leach liquor. The saturated amine, assaying 6.5 grams $\mathrm{U}_{3} \mathrm{O}_{8}$ per liter was stripped at several organic to aqueous ratios using $2 \mathrm{M} \mathrm{HCl}$ as the stripping solution. The stripping isotherm is shown in Figure 2.

An examination of Figure 2 reveals several important factors concerning the system. First, the uranium concentration in the organic phase remains constant at about 1 gram $\mathrm{U}_{3} \mathrm{O}_{8}$ per liter as the aqueous uranium concentration varied from 5 grams $\mathrm{U}_{3} \mathrm{O}_{8}$ per liter to 60 grams $\mathrm{U}_{3} \mathrm{O}_{8}$ per liter. Thus, it would appear that the saturation loading of uranium in the amine from $2 \mathrm{M} \mathrm{HCl}$ is 1 gram $\mathrm{U}_{3} \mathrm{O}_{8}$ per liter. The $\mathrm{ab}-$ sorbed uranium specie appears to be $\mathrm{UO}_{2} \mathrm{Cl}_{4}{ }^{-2}$ and is easily stripped from the solvent with water. 'It should be-pointed out, however, that under the conditions employed in determining the stripping isotherm, the aqueous environment changes radically as the uranium concentration bullds up in the stripping solution, since chloride is removed from the aqueous phase by amine while sulfate is discharged to the aqueous phase along with uranium. Therefore, the isotherm does not give an accurate indication of the saturation loading of $\mathrm{UO}_{2} \mathrm{Cl}_{4}^{-2}$ in the amine from $2 \mathrm{M} \mathrm{HCl}$ containing no sulfate. This fact is of some importance since in a countercurrent system, the final stage will be virtually free of sulfate and concentrated in chloride. Laboratory tests indlcate the true saturation loading from $2 M \mathrm{HCl}$ to be about 1.8 grams

Secondly, and most important, if the isotherm of Figure 2 is applicable to a multistage countercurrent system (and there is no guarantee of this because of the number of components in the system) a means of stripping tertiary amine efficiently with $2 \mathrm{M} \mathrm{HCl}$ is indicated. This opinion is based upon the fact that the uranium concentration in the solvent remained independent of the uranium concentration in the hydrochloric acid as the aqueous uranium concentration increased from 5 grams $\mathrm{U}_{3} \mathrm{O}_{3}$ per liter to 60 grams $\mathrm{U}_{3} \mathrm{O}_{\mathbf{8}}$ per liter and on the additional knowledge that 
the uranyl chloride complex can be stripped from the organic phase with water. Thus, it should be possible to take the stripped organic, bearing 1 gram $\mathrm{U}_{3} \mathrm{O}_{8}$ per Iiter as the uranyl chloride complex, and strip out the uranium with water. This water wash, now rich in uranium, can be mixed with $12 \mathrm{M} \mathrm{HCl}$ to give a $2 \mathrm{M} \mathrm{HCl}$ solution. The $2 \mathrm{M} \mathrm{HCl}$ could then be used in the stripping circuit and despite the fact considerable uranium is present in fresh stripping solution, no increase in the uranium concentration of the stripped organic should take place.

The system described above was tested using the flow sheet shown in Figure 3. The feed was a leach liquor prepared from a blend of Plateau ores. The liquor originally assayed 0.9 gram $\mathrm{U}_{3} \mathrm{O}_{8}$ per liter. It was spiked with uranium by the addition of yellow cake to give a uranium concentration of 1.5 grams $\mathrm{U}_{3} \mathrm{O}_{8}$ per liter. This was done to increase the flow rates in the stripping circuit, which otherwise would have been too low to be controlled accurately.

The extraction circuit consisted of four stages of mixersettlers. The aqueous flow rate was $390 \mathrm{ml}$ per minute and the organic flow rate was $90 \mathrm{ml}$ per minute. The solvent was $0.1 \mathrm{M}$ Alamine in kerosene containing 5 per cent PDA. The pregnant organic assayed 6.5 grams $\mathrm{U}_{3} \mathrm{O}_{8}$ per liter and over-all uranium extraction was 99.8 to 99.9 per cent.

The pregnant organic was washed in a single stage with $0.5 \mathrm{M} \mathrm{H}_{2} \mathrm{SO}_{4}$ at an organic to aqueous ratio of 7 . to 1 . The purpose of the wash step was, as before, to remove small quantities of entrained leach liquor and to strip out any extracted phosphate. The wash strip removed about 1 per cent of the uranium. The wash solution would normally be used in the leach circuit, but in this instance was simply discarded.

The pregnant organic was next stripped in three mixersettler stages using $2 \mathrm{M} \mathrm{HCl}$ at an organic to aqueous ratio of 12 to 14 to 1 . The $2 M \mathrm{HCl}$, which was made from the water scrub of the stripped solvent, contained 20 to 30 grams $\mathrm{U}_{3} \mathrm{O}_{8}$ per liter when introduced to the circuit, and the pregnant strip averaged 80 grams $\mathrm{U}_{3} \mathrm{O}_{8}$ per liter. (It is felt that a pregnant strip assaying 90 to 100 grams $\mathrm{U}_{3} \mathrm{O}_{8}$ per liter could be produced by this flowsheet, but it was difficult to control the very low flow rates.) The stripped organic, containing 1 to 1.5 grams $\mathrm{U}_{3} \mathrm{O}_{8}$ per liter, was sent to the water-scrubbing circuit. 
The scrubbing circuit consists of two stages of mixersettlers. The uranyl chloride was removed from the organic with water at an organic to aqueous ratio of about 20 to 1 . The solvent leaving the scrub circuit assayed 0.05 gram $\mathrm{U}_{3} \mathrm{O}_{8}$ per liter while the pregnant scrub assayed 30 grams $\mathrm{U}_{3} \mathrm{O}_{8}$ per liter. The solvent was recycled to the extraction circuit. The aqueous phase, was mixed with $12 \mathrm{M} \mathrm{HCl}$ to give a $2 \mathrm{M} \mathrm{HCl}$ solution to be used in the stripping circuit.

The flow sheet described above was tested for 100 hours and was at equilibrium for the last 40 hours. The results indicated that a tertiary amine could be efficiently stripped of uranium using the modified flow sheet.

Since an even higher concentration of uranium was desired for the feed solution to the green salt precipitation circuit, the feasibility of using a $3 \mathrm{M} \mathrm{HCl}$ stripping solution was investigated. A stripping equilibrium isotherm obtained by contacting pregnant organic, a tertiary amine, with $3 \mathrm{M} \mathrm{HCl}$ at several organic to aqueous ratios is shown in Figure 4. The uranium remaining in the organic phase was easily stripped with water. The uranium concentration in the organic phase remained at approximately 2 grams $\mathrm{U}_{3} \mathrm{O}_{8}$ per liter to 140 grams $\mathrm{U}_{3} \mathrm{O}_{8}$ per liter. It appeared that the same type of stripping circuit used for $2 \mathrm{M} \mathrm{HCl}$ stripping could be applied to $3 \mathrm{M} \mathrm{HCl}$ stripping.

The flow sheet used for the $3 \mathrm{M} \mathrm{HCl}$ stripping circuit is shown in Figure 5. It consists of 4 stages of uranium extraction, 1 stage of washing with $0.5 \mathrm{M} \mathrm{H} \mathrm{H}_{2}, 3$ stages of contact of the pregnant solvent with $3 \mathrm{M} \mathrm{HCl}$ and 3 stages of water stripping. The aqueous feed was the leach liquor prepared from a blend of Plateau ores and assayed 0.7 gram $\mathrm{U}_{3} \mathrm{O}_{8}$ per liter. The uranium content of the leach liquor was increased to 3.2 grams $\mathrm{U}_{3} \mathrm{O}_{8}$ per liter by the addition of yellow cake in order to obtain higher flow rates in the stripping circuit.

The extraction circuit consisted of four stages of internal mixer-settlers. The organic solvent contained $0.1 \mathrm{M}$ Alamine in kerosene containing 7 volume per cent PDA. An aqueous to organic ratio of 2.1 to 1 was maintained in the extraction circuit. The pregnant organic assayed 6.8 grams $\mathrm{U}_{3} \mathrm{O}_{8}$ per liter and the over-all uranium extraction was 99.9 per cent. 
The pregnant solvent was then washed in one stage with a $0.5 \mathrm{M} \mathrm{H}_{2} \mathrm{SO}_{4}$ solution at an organic to aqueous ratio of 12 to 1 . This step served the same purpose as the wash in the $2 \mathrm{M} \mathrm{HCl}$ stripping study.

The pregnant organic phase containing 6.7 grams $\mathrm{U}_{3} \mathrm{O}_{8}$ per liter was then contacted in three stages of external mixersettlers with a $3 \mathrm{M} \mathrm{HCl}$ solution assaying 141 grams $\mathrm{U}_{3} \mathrm{O}_{8}$ per liter at an organic to aqueous ratio of 16 to 1 . The $3 \mathrm{M} \mathrm{HCl}$ solution was prepared from $12 \mathrm{M} \mathrm{HCl}$ and the uranyl chloride solution obtained from the water wash circuit. Use of $12 \mathrm{M} \mathrm{HCl}$ to adjust the molarity resulted in a 25 per cent dilution. The resulting pregnant strip solution assayed 110 grams $\mathrm{U}_{3} \mathrm{O}_{8}$ per liter. In this circuit, the net result of the $3 \mathrm{M} \mathrm{HCl}$ contact was a conversion of the organic phase from the sulfate cycle to the chloride cycle and also some extraction of the uranyl chloride present in the $3 \mathrm{M} \mathrm{HCl}$ solution used for stripping. A much more concentrated strip solution would be obtained if anhydrous HCl were used rather than $12 \mathrm{M} \mathrm{HCl}$ to make up the $3 \mathrm{M} \mathrm{HCl}$ stripping solution.

The pregnant organic phase, now assaying 8.3 grams $\mathrm{U}_{3} \mathrm{O}_{8}$ per liter, was contacted with water in three stages of external mixer-settlers. The organic to aqueous ratio was 22 to 1 . The resultant organic phase, assaying 0.1 gram $\mathrm{U}_{3} \mathrm{O}_{8}$ per liter, was recycled to the extraction circuit. The water scrub, assaying 180 grams $\mathrm{U}_{3} \mathrm{O}_{8}$ per liter, was adjusted to $3 \mathrm{M} \mathrm{HCl}$ with $12 \mathrm{M} \mathrm{HCl}$.

This circuit was operated at equilibrium for 40 hours and the results demonstrated that efficient stripping could be obtained while producing a concentrated, highly pure uranium solution.

\section{Erom Concentrate Ieach Iiquors}

The solvent extraction system described for ore leach liquor extraction was modified so as to be applicable to the treatment of uranium concentrates.

Yellow cake was dissolved in sulfuric acid. It was found that by leaching hot for several hours, complete uranium dissolution could be obtained by maintaining the $\mathrm{pH}$ at about 1. An arbitrary uranium concentration of 100 grams $\mathrm{U}_{3} \mathrm{O}_{8}$ per liter was set for the pregnant liquor. Under these conditions, 
uranium dissolution of 99.99 per cent was achieved at a sulfuric acid consumption of about one pound per pound of $\mathrm{U}_{3} \mathrm{O}_{8}$. This solution, however, cannot be solvent extracted efficiently by an amine unless the amine is first converted to the sulfate form. This is due to a deficiency of sulfate in the system, since three moles of sulfate are required for each mole of uranium present. Extraction isotherms obtained by contacting the leach liquor with an amine sulfate and an amine chloride are shown in Figure 6. As can be seen, the amine chloride gives very poor extraction.

Since the chloride stripped amine cannot be used directly in the extraction circuit, a means of converting the amine to the sulfate form was devised. This was accomplished by first washing the amine with 10 per cent aqueous sodium carbonate. Using two stages for this conversion, the sodium carbonate consumption is slightly in excess of the stoichiometric requirement.

The amine, after the carbonate treatment, exists as the free amine. The amine is converted to the sulfate by washing with a stolchiometric quantity of one molar sulfuric acid. The sulfated amine is then used in the extraction circuit. The reactions involved in these operations are listed below.

Extraction

$$
2\left(\mathrm{R}_{2} \mathrm{NH}_{2}\right)_{2} \cdot \mathrm{SO}_{4}+\mathrm{UO}_{2} \mathrm{SO}_{4} \rightleftharpoons\left(\mathrm{R}_{2} \mathrm{NH}_{2}\right)_{4} \mathrm{UO}_{2}\left(\mathrm{SO}_{4}\right)_{3}
$$

Stripping

$$
\left(\mathrm{R}_{2} \mathrm{NH}_{2}\right)_{4} \mathrm{UO}_{2}\left(\mathrm{SO}_{4}\right)_{3}+4 \mathrm{HCl} \rightleftharpoons 4 \mathrm{R}_{2} \mathrm{NH}_{2} \mathrm{Cl}+\mathrm{UO}_{2} \mathrm{SO}_{4}+2 \mathrm{H}_{2} \mathrm{SO}_{4}
$$

Conversion to Free Amine

$$
2 \mathrm{R}_{2} \mathrm{NH}_{2} \mathrm{Cl}+\mathrm{Na}_{2} \mathrm{CO}_{3} \longrightarrow 2 \mathrm{R}_{2} \mathrm{NH}+2 \mathrm{NaCl}+\mathrm{CO}_{2}+\mathrm{H}_{2} \mathrm{O}
$$

Conversion to Sulfate

$$
2 \mathrm{R}_{2} \mathrm{NH}+\mathrm{H}_{2} \mathrm{SO}_{4} \longrightarrow\left(\mathrm{R}_{2} \mathrm{NH}_{2}\right)_{2} \mathrm{SO}_{4}
$$

The flow sheet for the treatment of concentrates is shown in Figure 7. This flow sheet utilizes a secondary amine. 
If a tertiary amine is used, the technique described earlier for stripping tertiary amines with hydrochloric acid must be used. Either $2 \mathrm{M} \mathrm{HCl}$ or $3 \mathrm{M} \mathrm{HCl}$ can be used for stripping.

Concentrated uranium feed for the green salt precipitation processs was obtained by solvent extracting sulfuric acid solutions of yellow cake. A typical analysis of a pregnant strip solution was as follows:

$$
\begin{gathered}
\mathrm{U}_{3} \mathrm{O}_{8} \text { - } 90 \text { grams per liter } \\
\mathrm{SO}_{4}=100 \text { grams per liter } \\
\mathrm{Cl}^{-}-17 \text { grams per liter } \\
\mathrm{H}^{+}-2 \text { Molar } \\
\mathrm{Mo}-1 \text { gram per liter } \\
\mathrm{Fe}, \mathrm{PO}_{4} \equiv-\text { traces }
\end{gathered}
$$

The feed solutions prepared from ores and concentrates by the amine extraction processes were used in the uranium reduction-precipitation studies. The results of these studies are presented in the rest of this report.

\section{PRECIPITATION OF URANIUM TETRAFLUORIDE BY THE CATALYTIC BEDUCTION PROCESS}

Many methods have been proposed for the wet chemical precipitation of uranium tetrafluoride. (Henceforth referred to as $\mathrm{UF}_{4}$ or green salt.) The majority of these methods fail to produce a product which can meet purity and density specifications. The initial investigation at this laboratory concerned itself with evaluating the most promising of these methods, the so-called Excer Process.

The Excer Process, developed at the Oak Ridge National Laboratory, utilizes an electrolytic cell to effect reduction of the uranium species and precipitation of UF 4.8 Depending on whether fluoride is present or not, the electrochemical cell can be used either to produce the salt directly or to produce a urenous solution which can subsequently be precipitated by the addition of fluoride. In order to fully evaluate this process an Excer Cell was constructed according to the specifications listed in ORNL-1979 and tests conducted. 
It will suffice to say that the main difference between the Excer Cell and other electrochemical cells is that an Ionics cation-exchange membrane is inserted between the mercury pool cathode and the lead anode. This creates two separate compartments. The membrane minimizes re-oxidation of uranium(IV) and protects the lead anode from the corrosive catholyte solution.

The Excer Process is continuous and necessitiates the withdrawal of the salt or urenous solution as it forms. The electrolytic cell, when used for direct precipitation, was operated at a temperature between $80^{\circ} \mathrm{C}$ and $90^{\circ} \mathrm{C}$ and from two to six hours. Tests employing this equipment resulted in the production of green salt which had a tap density* of between 2.5 and 3.0 grams per cc. The salt produced was analyzed and had a composition corresponding to the compound $\mathrm{UF}_{4} \cdot 3 / 4 \mathrm{H}_{2} \mathrm{O}$. Spectrographic and chemical analysis of this salt indicated it to be exceedingly pure. The only contamination resulted from droplets of mercury accompanying the salt from the catholyte chamber. In order to achieve a high recovery of uranium from the feed solutions, it was necessary to recycle the catholyte solution. Employing one recycle, tails of 0.50 grams $\mathrm{U}_{3} \mathrm{O}_{8}$ per liter could be obtained.

Tests were also run in which uranium(IV) solutions were prepared in the cell and green salt precipited by the addition of dilute hydrofluoric acid to the solution. In these tests, the tap density of the salt always fell between 1.0 and 2.0 grams per cc. The difference in tap density between salt produced by direct precipitation and salt produced by addition of fluoride to a uranous solution can be explained by the fact the former salt is crystalline and the latter flaky. In the external precipitation tests, the overall recovery remained about the same and the purity improved slightly since no mercury contamination was encountered.

The chemical performance of the cell during the test period was excellent. The reaction was reasonably efficient with a 10 per cent excess of fluoride, and the uranium loss to the anode compartment was nil. However, certain difficulties

*Tap Density is the weight of salt that can be packed in a graduate by moderately tapping the vessel. 
did arise due to the mechanical nature of the cell. It was necessary to devise a new method of salt withdrawal since the dense salt tended to stay at the bottom of the cathode compartment. Also special care had to be taken to avoid the formation of a gas bubble on the membrane surface in the cathode compartment. When this happened, the cell resistance increased markedly. Another problem was the difficulty of reproducing results from day to day. It was felt that the electrolytic cell was a fine bench-scale tool, but that it would not be practical in plant-scale production.

The information gathered from this initial investigation was extremely valuable in our subsequent work. It was obvious that if a dense salt were to be produced, the uranium would have to be reduced in the presence of fluoride. The presence of fluoride in the uranium-bearing solution also serves to shift the uranium(IV)-uranium(VI) oxidation potential to a more negative value (from $-0.4 \mathrm{v}$ to $-0.7 \mathrm{v}$ ) and thus allows a wider choice of reducing agents.

Our investigation was directed toward the development of a process which would incorporate a cheap, chemical reducing agent. Such a reagent would have to be a rapid reductant, soluble in the oxidized and reduced states in the feed solution, and show no tendency to coprecipitate with the salt. In order to acquire information about reducing agents, a screening program was undertaken.

\section{Screening of Chemical Reducing Agents}

In the search for chemical reducing agents, no restrictions were made concerning the cost of the reagent. It was felt that the screening program could best be accomplished if as many reagents as possible were tested and the better reagents, chemically and costwise, proposed for further study.

Many reducing agents were found to effectively reduce uranium in the presence of fluoride and subsequently precipitate $\mathrm{UF}_{4}$. For identification purposes these reductants were broken down into three classes. The first class includes all reductants added as solids, the second class includes all reducing agents added in aqueous solutions, and the third class includes all catalytic reducing systems. The following is a list of the 
reagents that precipitated $\mathrm{UF}_{4}$ from hot uranyl fluoride solutions.*

Solid

Reductants

$\mathrm{Al}^{\circ}$
$\mathrm{Cu}^{\circ}$
$\mathrm{Fe}^{\circ}$
$\mathrm{Zn}^{\circ}$
Water

Seluble Reductants

$\mathrm{CuCl}$

$\mathrm{CrCl}_{2}$

$\mathrm{FeCl}_{2}$

$\mathrm{SnCl}_{2}$

$\mathrm{TiCl}_{3}$
Catalytic Reduction Systems

$\mathrm{NH}_{2} \mathrm{OH} \cdot \mathrm{HCl}+\mathrm{Cu}^{++}+\mathrm{Cl}^{-}$ $\mathrm{N}_{2} \mathrm{H}_{4} \cdot \mathrm{H}_{2} \mathrm{SO}_{4}+\mathrm{Cu}^{++}+\mathrm{Cl}^{-}$ Ascorbic Acid $+\mathrm{Cu}^{++}+\mathrm{Cl}^{-}$ $\mathrm{SO}_{2}+\mathrm{Cu}^{++}+\mathrm{Cl}^{-}$

\section{Solid Reductants}

Generally speaking, the solid reductants were only briefly tested. Whether the reagents were added as finely divided powders or as rods dipping into the solution, the reactions were much too fast and the contamination problem too great. An extremely fast reaction results in a very fluffy type of precipitate. (Tap Density - 1.0 to 1.5 grams per cc). Of the solids tested, only freshly precipitated copper metal showed any promise at all. The reaction with copper was just slow enough to permit the formation of a reasonably dense product. (Tap Density - around 2.2 grams per cc).

\section{Water Soluble Reductants}

The water soluble reducing agents, except for $\mathrm{TiCl}_{3}$, were rather thoroughly tested. Ferrous and cuprous chloride are normally unable to reduce significant amounts of uranium(VI). However, in the presence of fluoride, both ferrous and cuprous ions are excellent reducing agents. This characteristic made the fluoride concentration a very important factor in working with these reagents. On the other hand, stannous and chromous chloride are very strong reducing agents. Even in the

\footnotetext{
*The method used to test these reducing agents and systems was as follows: either 500 or $1000 \mathrm{ml}$ of a solution containing 102 grams per liter $\mathrm{U}_{3} \mathrm{O}_{8}, 100$ grams per liter $\mathrm{SO}_{4}=17.4$ grams per liter $\mathrm{Cl}^{-}$, and 2 molar in free acid was heated to $70^{\circ} \mathrm{C}$ to $90^{\circ} \mathrm{C}$ and various quantities of 48 per cent $\mathrm{HF}$ added. The reducing agent was added in a stoichiometric quantity while the fluoride concentration was either stoichiometric or 100 per cent excess. The uranium solutions were prepared by solvent extraction as described previously.
} 
absence of fluoride these reagents reduce uranium(VI) to uranium(IV). Due to the unstable nature of this reagent, chromous chloride had to be freshly prepared before use. This was accomplished by passing a weak hydrochloric acid solution of chromium(III) through a Jones reductor.

Green salt produced during these tests was a light to medium green-colored crystalline material. The tap densities ranged from 2.0 to 3.4 grams per cc. This large variation in tap density was surprising since most of the experiments were performed in the same way. However, the higher densities did suggest that it was entirely feasible to prepare a dense $\mathrm{UF}_{4}$ by wet chemical reduction and precipitation. Also, the contamination of green salt by the reducing agents was not excessive. Salt prepared by stannous chloride reduction contained the greatest contamination, around 1000 PPM, while salt prepared by the other reagents contained about 100 PPM. Salt from these runs was determined to have the composition $\mathrm{UF}_{4} \cdot 3 / 4 \mathrm{H}_{2} \mathrm{O}$.

\section{Catalaytic Reduction Systems}

During the search for new reductants, it was found that sulfur dioxide gas would not reduce uranium even in the presence of excess fluoride. However, it was observed that sulfur dioxide would reduce cupric ion to cuprous fon at elevated temperatures in the presence of a small quantity of chloride. Since the uranium solution from which the uranium was to be precipitated contained chloride, it was apparent that if a small quantity of copper ion were added, and sulfur dioxide gas passed into the hot solution, uranium tetrafluoride would be precipitated. This was found to be the case. It was also found that 1-ascorblc acid, hydroxylamine hydrochloride, and hydrazine sulfate, which can only precipitate small quantities of $\mathrm{UF}_{4}$ from uranium solutions containing excess fluoride, could be substituted for sulfur dioxide. In these systems cupric copper is considered to be a catalyst. Sulfur dioxide, 1-ascorbic acid, hydroxylamine hydrochloride, and hydrazine sulfate are the reducing agents since they regenerate the catalyst and actually control the reduction. It cannot be too strongly emphasized that chloride ion is needed for the reduction of cupric copper by sulfur dioxide and consequently is necessary to promote the catalytic precipitation of $\mathrm{UF}_{4}$ by sulfur dioxide and copper. 
Green salt precipitated by catalytic reduction was a dark green-colored crystalline material having a tap density between 2.60 and 3.36 grams per cc. Copper contamination in the salt was about 40 PPM or less.

The reduction system of copper and sulfur dioxide was investigated further in a series of tests which are summarized in Table 1. In the previous tests, a Pyrex reaction vessel had been used, but it was observed that some silica dissolved and decreased the free fluoride ion concentration by formation of a soluble silicon fluoride complex. For these and subsequent tests, the reaction vessel was lined with $\mathrm{Kel}-\mathrm{F}$.

These results clearly indicated that dense green salt, free of copper and sulfate, could be precipitated from hydrochloric acid strip solutions with only moderate reagent concentrations. The efficiency of the precipitation in most cases was excellent while the tap density was consistently high. The running time was still somewhat uncertain but a reaction time of six hours seemed reasonable. It should be pointed out that in Table 1 no mention is made of chloride concentration. As will be shown later in the report, the chloride concentration is an important factor in regard to reaction time. The chloride concentration has been omitted since two different feed solutions were used (having different chloride assays) and since the copper was added in some tests as $\mathrm{CuCl}_{2} \cdot 2 \mathrm{H}_{2} \mathrm{O}$ and in others as $\mathrm{CuSO}_{4} \cdot 5 \mathrm{H}_{2} \mathrm{O}$.

Having completed the preliminary screening of reducing agents and reduction systems for the production of $\mathrm{UF}_{4}$, it was decided to thoroughly investigate the copper-sulfur dioxide gas-catalytic reduction process. The advantages of such a system seemed to be numerable and the reagents readily available and cheap. The following is a list of the more outstanding advantages that this process has over other methods for wet chemical precipitation of $\mathrm{UF}_{4}$.

1. The system and equipment is simple and easy to operate.

2. The reagents involved are cheap and readily available.

3. No volume change occurs during the reaction. This keeps

$\mathrm{UF}_{4}$ solubility at a minimum.

4. The reaction is easily controlled.

5. Contamination by reagents is at a low level. Copper showed no tendency to contaminate the salt and the oxidation product of $\mathrm{SO}_{2}$ is $\mathrm{SO}_{4}=$, which is already present in the solution in large quantity. 
WIN -90

6. The use of gas results in a homogeneous type of precipitation, which is conducive to good crystal growth and low impurity occlusion.

7. This method consistently produces salt of the desired density.

8. If it were necessary to recover the excess reducing agent, this could be accomplished by liquification of the exit gas at minus $10^{\circ} \mathrm{C}$.

\section{Equipment and Experimental Procedures}

During the course of the investigation, three reaction vessels of similar design were used. These vessels contained 1,10 , and 40 liters of solution. In Figure 8 the 40-liter reaction vessel is illustrated. The inner wall was coated with Kel-F in order to handle the extremely corrosive solutions. The sulfur dioxide gas line was made of hard rubber which was capped with a rubber frit to afford greater dispersion of the gas. An exit line was provided in the tank by tapping an acid resistant valve into the base of the vessel. Thermocouples were placed in the top, middie, and bottom portions of the tank to determine that the heating was uniform. The vessel was provided with a Plexiglass cover to contain any splashing of the solution and to channel the exit gas out of one central opening in the cover. Stirring was accomplished by a tubular hard rubber stirrer, capped at the open ends. To enhance the stirring action, four baffles were constructed into the walls of the vessel.

In order to establish the process variables of reaction time, temperature, stirring, and gas flow rate, a general operating procedure was decided upon. The concentrations of copper and fluoride expressed in this procedure were chosen from Table 1. These values are substantiated as being approximately optimum by the work shown later in this report. The question of chloride concentration, as previously stated, is also discussed later in this report. However, it has been found that the hydrochloric acid strip solutions contain sufficient chloride of themselves to facilitate the reduction of cupric copper by sulfur dioxide in a reasonable time. The following testing procedure was used.

1. An appropriate volume of solution containing uranium, chloride, and sulfate was charged to the reaction vessel. 
WIN-90

2. Copper sulfate pentahydrate was added at a concentration of 0.185 moles of copper per mole of uranium present.

3. Fifty per cent hydrofluoric acid was added so that the solution contained four moles of fluoride per mole of uranium present plus 14 grams per liter of (free) excess fluoride.

4. The solution was heated, with adequate stirring, to between $80^{\circ} \mathrm{C}$ and $95^{\circ} \mathrm{C}$.

5. Sulfur dioxide gas was allowed to bubble through the solution at a slow, steady rate so as to maintain a saturated solution.

6. At the completion of runs, the heat, stirring, and gas flow were stopped and the salt allowed to settle.

7. The mother liquor was decanted off and the salt washed with water and dried in an oven at $110^{\circ} \mathrm{C}$.

\section{Recovery Rate with Increasing Uranium Concentration}

Previous data (Table l) has shown that it is possible to effect an excellent recovery of uranium as green salt from a solution which contains only moderate quantities of copper and fluoride. A reaction time of six hours seemed to be adequate. Since these data were complled for essentially one concentration of uranium, a series of tests were run in which the uranium concentration was increased over a range of 60 to 200 grams of $\mathrm{U}_{3} \mathrm{O}_{8}$ per liter. The reaction time was constant at six hours while the reagent concentrations were those listed in the experimental procedure. Data obtained in these runs are reported in Table 2 .

These results indicate that with a saturated solution of sulfur dioxide, the recovery should increase as the feed concentration is increased. This happens because the solution after precipitation contains between 0.10 and 0.15 grams per liter $\mathrm{U}_{3} \mathrm{O}_{8}$, which is the solubility of $\mathrm{UF}_{4} \cdot 3 / 4 \mathrm{H}_{2} \mathrm{O}$ in this solution. No difficulty was encountered in contamination due to the increased copper concentration. The copper costs are the same regardiess of the feed concentration since the copper to uranium ratio is constant. 
Our procedure is based on a fixed concentration of excess fluoride rather than on a mole for mole excess. As Figure 9 demonstrates, the economics of the operation improve with the higher feeds. The excess concentration of fluoride probably could be dropped to a lower value if there was a willingness to accept longer reaction times. Employing the solvent extraction techniques developed in conjunction. with this work, a feed solution of between 100 and 1.10 grams of $\mathrm{U}_{\mathbf{3}} \mathrm{O}_{8}$ per liter can easily be obtained. Such a feed would closely approximate that used in Run 5, Table 2. In which case, the excess fluoride needed for a six-hour reaction time will cost about 2.5 cents per pound of $\mathrm{UF}_{4} \cdot 3 / 4 \mathrm{H}_{2} \mathrm{O}$ produced.

\section{Reaction Temperature}

A series of tests were run to determine the optimum solution temperature for the catalytic reduction and precipitation of green salt. Preliminary considerations are that high temperatures $\left(80^{\circ} \mathrm{C}\right.$ to $\left.100^{\circ} \mathrm{C}\right)$ help the speed of the over-all reaction and the density of the salt, while the lower temperatures (around $70^{\circ} \mathrm{C}$ to $80^{\circ} \mathrm{C}$ ) cause a greater absorption of sulfur dioxide gas in the solution. The approach was to select that temperature which would allow the best recovery and the densest salt for a six-hour run.

Four experiments were run at temperatures of $73^{\circ} \mathrm{C}, 83^{\circ} \mathrm{C}, 93^{\circ} \mathrm{C}$, and $103^{\circ} \mathrm{C}$. In each case, the feed composition and precipitation conditions were identical except for the temperature. After the reactions started, the solutions were periodically sampled to determine the quantity of uranium precipitated. Rate curves were plotted for the temperatures investigated and are shown in Figures 10, 11, 12, and 13 .

Analysis of the rate curves and density data shows that the lower temperature $\left(73^{\circ} \mathrm{C}\right)$ fails to produce the desired density salt, while the high temperature $\left(103^{\circ} \mathrm{C}\right)$ fails to produce the necessary rate of precipitation in six hours. Green salt produced at $73^{\circ} \mathrm{C}$ is not the crystalline 0.75 hydrate but a more bulky type of precipitate. It has been the experience of this laboratory that these bulky precipitates are higher hydrates and much less dense than the 0.75 hydrate. Aside from the density of the salt, the reaction at $73^{\circ} \mathrm{C}$ was much slower than expected. Apparently, the added solubility of sulfur dioxide does not compensate for the decreased reaction rate at lower temperatures. At $103^{\circ} \mathrm{C}$ the salt was extremely dense but the reaction rate very slow. This 
temperature is the approximate boiling point of the feed solution. It is felt that this causes such a low solubility of sulfur dioxide gas in the solution that the reaction rate is limited.

The rate curves for precipitations at $83^{\circ} \mathrm{C}$ and $93^{\circ} \mathrm{C}$ are nearly identical. Uranium tails produced in six hours are 0.10 gram per liter $\mathrm{U}_{3} \mathrm{O}_{8}$, while the salt was sufficiently dense to be acceptable. The choice of temperature for the reaction is not too critical between $85^{\circ} \mathrm{C}$ and $95^{\circ} \mathrm{C}$. However, the desire for higher density salt led to the establishment of a reaction temperature of between $93^{\circ} \mathrm{C}$ and $95^{\circ} \mathrm{C}$ as standard for subsequent testing.

\section{Stirring as a Variable}

One of the most difficult variables to evaluate for this process is the rate and type of stirring that is required during precipitation for the production of a dense salt. Since testing was confined to 500-ml volumes, data collected on this scale are not applicable to runs processing large volumes of solution. Therefore, it was more feasible to establish just how much of a variable stirring was, rather to identify the exact type of stirring needed.

Five tests were run in which the stirrer speed and position of the stirrer in the solution were varied. For these tests, the feed solution was identical to that used for the temperature study. The precipitations were all conducted at $93^{\circ} \mathrm{C}$.

The results of these tests, shown in Table 3, indicate that some type of stirring is necessary to produce a salt with a tap density of over 3.0 grams per cc. With no stirring at all, the homogeneous precipitation was still quite effective producing a fine crystalline material which had a tap density of 2.40 grams per cc. This salt represents the lower density limit which can be produced by this process at $93^{\circ} \mathrm{C}$. Also, it is of interest to note that the stirrer speed or position has no effect on the over-all recovery of uranium from the feed solutions.

In the course of work performed at this laboratory, no pronounced stirring problems have been encountered. Care was taken to avoid any such situation in the design of the 40liter precipitation unit. The stirrer design and baffles 
afforded such a turbulance in the solution that the salt was completely suspended.

\section{Larger Scale Production of $\mathrm{UE}_{4} \cdot 3 / 4 \mathrm{H} / \mathrm{O}$}

In order to obtain sufficient green salt for drying studies and metal reduction bomb tests, the process was scaled up to produce from one to thirteen pounds of salt per run. This scale-up also afforded an opportunity for calculating the efficiency of the sulfur dioxide reductant. It was hoped that these runs would indicate any difficulties that might be encountered in a pilot plant run.

Data obtained from these runs are reported in Table 4. Runs 1 through 7 were performed at the Winchester Laboratory, whil e Runs 8,9 , and 10 were performed at National Lead refinery at Fernald, Ohio. The first few runs were made to observe possible variations in uranium recovery and salt density. Consequently, the sulfur dioxide level was kept between 100 and 200 per cent excess. This initial fifteen-fold scale-up was extremely successful. The precipitation was completed in the pre-determined six hours and the uranium recovery and salt density were in accordance with data collected for small volume tests.

The sulfur dioxide concentration was then cut back to only 50 per cent over stoichiometric. The decreased flow rate of gas did not necessitate additional reaction time. It is felt that with this excess, the solution remains essentially saturated with sulfur dioxide throughout the run. Possibly, this excess could be further reduced. However, because of the low reagent cost of sulfur dioxide, further study was not warranted.

Runs 8, 9, and 10 represent another scale-up. Here again, the process worked extremely well. These three runs were conducted under the optimum conditions determined by the test program.

At the completion of precipitation, the salt was washed with water by decantation and filtered. It was then oven dried at $110^{\circ} \mathrm{C}$. Since this salt is a hydrate, the final step was to dehydrate the material. Investigations at this laboratory have led to the development of a very simple and effective means of dehydration. (This dehydration study will be the subject matter of a separate report.) Having been dehydrated, 
the salt was then subjected to bomb reduction for uranium metal preparation. As far as can be determined from preliminary tests, the dehydrated $\mathrm{UF}_{4}$ produced by the catalytic reduction process is amenable for reduction to uranium metal.

\section{Physical Properties of Prepared Green Salt}

Green salt precipitated by the catalytic reduction process is a dark green crystalline material. Microscopic examination of the salt shows it to be composed of round balls, agglomerates of particles, and small elliptical shaped particles. The main body of the salt is made up. of agglomerates and particles with only a few round balls.

As a function of temperature, tap density increases as the temperature of the precipitating solution is raised to a value of $85^{\circ} \mathrm{C}$ or higher. At temperatures of $85^{\circ} \mathrm{C}$ or above, tap density follows no set pattern but rather tends to level off at a value of $3.15 \pm 0.15$ grams per cc.

Tap density was also studied as a function of particle size distribution. Six green salt samples, having tap densities of from 2.75 to 3.45 grams per cc, were subjected to dry screen analysis. Data obtained in these tests, which is shown in Table 5, fail to give any definite information concerning a density dependence on particle size. In all cases the material was very fine with the first appreciable fraction collecting on a 270-mesh screen. Minus 400mesh material represented the largest fraction and was at least 40 per cent of the total weight for the samples tested. The only conclusions that can be drawn from these data are that either the screen analysis was not accurate enough to pick up any trend or else the breakdown of the minus 400-mesh material is the regulating factor for tap density.

The solubility of $\mathrm{UF}_{4} \cdot 3 / 4 \mathrm{H}_{2} \mathrm{O}$ has been determined in cold water and in a hot acid solution simulating a barren solution from the precipitation step. In both cases the solubility 
is approximately 0.15 gram per liter. Washing studies were also conducted on this same lot of green salt to determine uranium loss during this operation. Figure 14 is a plot of the solubility of green salt versus the time of contact with the wash solution. The values expressed in this curve, for 5- and 10-minute wash periods, are somewhat higher than the solubility of the salt. This was due to the formation of a colloidal suspension of peptized green salt. This effect is seldom encountered in actual washing operations.

The wash rate of a filter cake of green salt was determined. It is possible to pass 1 liter of wash water through a 1-inch thick cake, 4.5 inches in diameter, in one minute.

The settling rate of green salt produced by the catalytic reduction process is 12 feet per hour. The major portion of the salt will settle at a rate of 30 feet per hour while the fines settled somewhat slower.

$\mathrm{UF}_{4} \cdot 3 / 4 \mathrm{H}_{2} \mathrm{O}$ prepared by the process described is extremely pure. Shown in Table 6 is a complete chemical analysis of a sample of $\mathrm{UF}_{4} \cdot 3 / 4 \mathrm{H}_{2} \mathrm{O}$ (Run 2, Table 4) prepared from a Plateau ore sample using the solvent processes described in this report. The high purity of the sample is attributed to two factors, selectivity of the solvent and the almost complete absence of occlusion of impurities by the precipitated salt. Indication of the decontamination attained in the precipitation process can be seen in Table 7 . These decontamination factors were determined by adding a known concentration of the element in question to the precipitation feed solution prior to the formation of the salt. The product was then analyzed to determine the quantity of impurity occluded. In the case of sulfate and molybdenum, these substances were already present in the precipitation feed solution, and it was not necessary to introduce additional quantities. The relatively low factors noted for zirconium and phosphate are attributed to the formation of insoluble compounds rather than occlusion. Uraniun(IV) phosphate precipitation is almost certainly the source of phosphate impurity. In the case of zirconium, it is felt that zirconium phosphate is being precipitated since the precipitation feed solutions contain traces of phosphate. 
WIN-90

Preparation of Other $\mathrm{U}^{+4}$ SaIts

Employing catalytic reduction, three other uranium(IV) salts have been prepared besides $\mathrm{UF}_{4} \cdot 3 / 4 \mathrm{H}_{2} \mathrm{O}$. When either sodium or ammonium is present in the feed solution, the salt. produced is a double salt. The molecular formula of these salts approximate $\mathrm{NaUF}_{5}$ and $\mathrm{NH}_{4} \mathrm{UF}_{5}$. Indications are that these salts are less soluble than $\mathrm{UF}_{4} \cdot 3 / 4 \mathrm{H}_{2} \mathrm{O}$. Solutions from which these double salts were precipitated contained only 0.05 gram per liter $\mathrm{U}_{3} \mathrm{O}_{8}$ while the usual barren solution contains 0.10 and 0.20 gram per liter $\mathrm{U}_{3} \mathrm{O}_{8}$. The double salts are" a light, yellow-green colored crystalline material having tap densities of 1.8 to 2.7 grams per cc.

If the fluoride is replaced by phosphate in the feed solution, It is possible to precipitate a hydrated uranous phosphate. The reaction is not as rapid as for UF 4 , with only about 50 per cent recovery in six hours. The precipitate tends to form a jelly-like substance as the reaction proceeds.

\section{Precipitation from Solutions lther Than Hydrochloric Acid} Strip Solutions

Green salt has been precipitated from feed solutions that were made by dissolving a yellow cake in sulfuric and hydrochloric acid. Samples of Monticello carbonate and Shiprock acid yellow cake were dissolved to make a solution which contained 60.0 grams per liter $\mathrm{U}_{3} \mathrm{O}_{8}, 0.5 \mathrm{M}$ hydrochloric acid, and were $1 M$ in free acid. The solutions were then run through the normal precipitation process. Uraniun recovery was excellent, being about 99.7 per cent. The salt produced was a light green-colored crystalline material having a tap density of 2.70 grams per cc for the Shiprock acid sample and 2.00 grams per cc for the Monticello carbonate sample.

Another test was made on a solution containing 200 grams of $\mathrm{U}_{3} \mathrm{O}_{8}$ per liter made from Shiprock yellow cake. The precipitation was 99.5 per cent complete, while the salt had a tap density of 2.75 grams per cc.

Spectrographic analysis of the yellow cakes and the green salt produced from them indicated that a sizeable decontamination can be effected by the precipitation step alone. The major contamination is sodium, which precipitates as the uranium fluoride-sodium fluoride double salt. 
Green salt has also been precipitated from nitric acid strip solutions from TBP solvent extraction circuits. Since these solutions do not contain chloride, this necessitates the addition of about 0.5 mole per liter of hydrochloric ac1d. The presence of nitrate complicates the over-all reaction somewhat. Sulfur dioxide gas by itself will reduce nitrate. In normal precipitating solutions, where copper and chloride are present, nitrate is reduced to nitrogen oxide (NO). This reaction is very efficient, producing nitrate tails of about 0.1 gram per liter. The subsequent reduction and precipitation of green salt follows the nitrate reduction without any deleterious effects. The recovery was 99.80 per cent, the salt contained no nitrate, and had a tap density of 3.20 grams per cc.

The use of nitrate solutions as feeds for the reduction process presents the problem of longer reaction times and larger sulfur dioxide consumption. Otherwise these feeds are entirely suitable for the process described in this report.

\section{VARTABIFS INVOIVED IN THE PRECIPITATION OF UE BY THE CATALYTIC} REDUCTION PROCESS

The effect of some of the variables involved in the precipitation of uranium tetrafluoride by the copper-sulfur dioxide catalytic reduction process were studied. The following equations represent the two pertinent reactions involved in the precipitation, and the over-all reaction:

$$
\begin{array}{r}
2 \mathrm{CuCl}_{4}=+\mathrm{SO}_{2}+2 \mathrm{H}_{2} \mathrm{O} \longrightarrow 2 \mathrm{CuCl}_{2}^{-}+\mathrm{SO}_{4}=+4 \mathrm{H}^{+}+4 \mathrm{Cl}^{-} \\
2 \mathrm{CuCl}_{2}^{-}+4 \mathrm{HF}+\mathrm{UO}_{2}^{++}+4 \mathrm{Cl}_{2}^{-+}+\left.\mathrm{UF}_{4}\right|_{+} ^{++} \mathrm{SuCl}_{4}++2 \mathrm{CH}_{2} \mathrm{O}
\end{array}
$$

The investigations in addition to a study of the over-all reaction, noted above (3), also included a brief study of each of the separate reactions involved, namely, the reduction of cupric ion to cuprous ion by sulfur dioxide (Equation 1) and the reduction of uranyl ion by cuprous ion to precipitate $\mathrm{UF}_{4}$ (Equation 2).

The precipitation of uranium tetrafluoride by the copper catalyzed sulfur dioxide reduction of uranium in the presence of fluoride is governed by a number of interrelated variables, 
such as the concentration of uranium, fluoride, chloride, copper, and sulfur dioxide. In addition, the effect of temperature was also studied.

Studies of the effects of these variables were carried out in a glass reaction vessel lined with Kel-F. Solutions 1.0 molar in sulfuric acid containing the desired concentrations of fluoride, chloride, copper, and uranium added as hydrofluoric acid, hydrochloric acid, cupric sulfate and uranyl sulfate were heated to $75^{\circ} \mathrm{C}$ and sulfur dioxide was bubbled through the solution during the reaction, so as to maintain a saturated solution. In this manner, the sulfur dioxide concentration remained essentially constant throughout the precipitation. These solutions were continuously agitated and samples were withdrawn at various intervals, filtered, and potassium permanganate was added in order to stop the reaction. The samples were then analyzed for the unprecipitated uranium.

The effect of uranium concentration on the precipitation rate was determined by precipitating uranium tetrafluoride from a solution originally 0.21 molar in uranfum. The fluoride concentration was sufficiently high so that there was no appreciable change in fluoride concentration during the precipitation. The temperature and the concentrations of all other reactants were maintained constant during the reaction. Figure 15 indicates that a plot of the $\log$ of the uranium concentration versus time yields a straight line, indicating that the reaction rate is first order with respect to uranium concentration.

No precipitation was noted from a solution 0.0178 molar in uranium, 0.0317 molar in copper, 0.563 molar in chloride and 0.0712 molar in fluoride, the stoichiometric fluoride requirement. Excess fluoride is necessary before the reaction can proceed in a reasonable period of time. Figure 16 indicates the effect of fluoride concentration on the rate of uranium precipitation. Increasing the fluoride concentration over a range from 0.33 molar to 1.12 molar resulted in an increase in the rate of precipitation which showed a first power dependence with respect to the fluoride concentration, in the fluoride concentration range 0.33 molar to 1.12 molar. When the fluoride concentration was increased above 1.12 molar, only a small increase in the rate was observed. 
These precipitation tests were allowed to run until analysis of the unprecipitated uranium showed that the precipitation had stopped. The amount of uranium remaining in solution was then attributed to the solubility of $\mathrm{UF}_{4}$ under the conditions of the test.

Figure 17 shows the effect of fluoride concentration on the solubility of $\mathrm{UF}_{4}$. As can be seen, increasing the concentration of fluoride decreases the solubility of $\mathrm{UF}_{4}$. However, this effect is not a pronounced one, an increase in the fluoride concentration from 0.26 molar to 1.56 molar resulted in a decrease in the solubility of $\mathrm{UF}_{4}$ from 0.25 grams of $\mathrm{U}_{3} \mathrm{O}_{8}$ per liter to 0.085 gram $\mathrm{U}_{3} \mathrm{O}_{8}$ per liter.

It should be noted in Figure 16, that there is an induction period prior to the precipitation of uranium tetrafluoride and that the length of this induction period is a function of the fluoride concentration. This induction period is also dependent upon the uranium concentration, the copper concentration, and the chloride concentration. This induction period appears to be the result of either of two possibilities: (a) a necessity of producing a finite cuprous ion concentration before the reaction can proceed or (b) the formation of a soluble complex prior to the precipitation.

Figure 18 shows the effect of the copper concentration on the rate of precipitation. Increasing the copper concentration from 0.0079 molar to 0.063 molar indicated the reaction was first order with respect to the copper concentration.

The reduction of cupric ion by sulfur dioxide does not take place in the absence of chloride. The chloride is necessary in order to stabilize the cuprous ion. Figure 19 shows the effect of chloride concentration on the rate of precipitation of uranium tetrafluoride. Increasing the chloride concentration from 0.018 molar to 1.12 molar resulted in a significant increase in the precipitation rate. However, an analysis of the data failed to reveal any consistent power dependency for the chloride concentration.

Figure 20 shows the effect of temperature on the precipitation rate. Increasing the temperature results in an increasing rate of precipitation until the solution approaches the boiling point, when a definite decrease in the rate is noted. This is due to the low solubility of sulfur dioxide at this temperature. The amount of uranium remaining in 
solution after the precipitation of UF had stopped was attributed to the solubility of $\mathrm{UF}_{4}$ at that temperature. Figure 21 shows the effect of temperature on the solubility of $\mathrm{UF}_{4}$.

\section{Reduction of Cupric Copper by Sulfur Dioxide}

In order to study the reduction of cupric copper by sulfur dioxide, a method was needed by which we would be able to determine either cupric or cuprous copper in the presence of a reducing agent, $\mathrm{SO}_{2}$, without disturbing the equilibrium of the system. Since none of the conventional. analytical procedures seemed applicable to this system, a potentiometric method for estimating the ratio of cupric to cuprous copper present in solution was adopted.

Redox titration curves were obtained for the reduction of cupric copper using chromous chloride. This reduction was carried out in a solution 1.0 molar in sulfuric acid and 0.6 molar in hydrochloric acid. The titration vessel consisted of a $250 \mathrm{ml}$ beaker closed with a rubber stopper with holes provided for the introduction of a gas inlet tube, a saturated calomel electrode, a platinum indicator electrode and a dispensing buret. A magnetic stirrer was used for agitation and nitrogen gas was bubbled through the solution prior to the titration to remove oxygen. In this manner standard curves were prepared relating EMF to the concentration of cuprous ion at $25^{\circ}, 60^{\circ}$, and $90^{\circ} \mathrm{C}$. These curves are presented in Figure 22 as a plot of EMF versus per cent cuprous copper.

Titration curves obtained when the solution was made 1.0 molar in hydrofluoric acid showed that the addition of fluoride had no effect on the potential at which cupric copper is reduced.

With these standard curves relating EMF to cuprous concentration available, it was now possible to study the rate of reduction of cupric ion by sulfur dioxide. Sulfur dioxide was bubbled through a solution .0316 molar in copper, 1.0 molar in sulfuric acid, and 0.6 molar in hydrochloric acid in a titration vessel identical to that used for the chromous reduction. The EMF was measured at various time intervals and by reference to the standard curves, these EMF readings were converted to cuprous concentrations. Figure 23 shows the effect of temperature on the rate of 
reduction of cupric ion by sulfur dioxide. The reaction proceeds very slowly at room temperature. If the temperature is increased, the rate of copper reduction also increases. However, even at $90^{\circ} \mathrm{C}$, only 60 per cent of the copper is reduced in six hours. These curves show a comparatively rapid initial rate of reduction after which the reaction rate levels off and proceeds only very slowly. It appears that the system is approaching equilibrium. The rate of copper reduction was found to be independent of the fluoride concentration.

\section{Reduction of Uranyl Ion by Cuprous Chloride}

Studies of the reduction of uranyl ion by cuprous chloride to precipitate uranium tetrafluoride indicated that no precipitation took place when stoichiometric concentrations of cuprous chloride and hydrofluoric acid were added to a 0.018 molar solution of uranyl ion. The use of excess concentrations of cuprous chloride and hydrofluoric acid resulted in a rapid rate of precipitation. Figure 24 shows the rate of precipitation when a 50 per cent excess of cuprous chloride was added to a uranium solution containing various amounts of excess fluoride. Above a 0.6 molar fluoride concentration, the reaction rate was so rapid that it was difficult to measure.

An examination of the variables affecting each of the separate reactions indicate that at low fluoride concentrations the second reaction, the reduction of uranyl ion, is the rate determining step, while at high fluoride concentrations, the first reaction, the reduction of copper by sulfur dioxide is the rate determining step. 


\section{IITERATURE CITED}

1. W. B. Lolley, "Precipitation of Uranium Ammonium Fluoride from UNH Solutions as an Intermediate in the Preparation of Uranium Tetrafluoride," HW-35814 (February 1, 1955).

2. I. R. Higgins and J. T. Roberts, "Chemical Development of the Excer Process, Part I," ORNI-1696 (April 13, 1956).

3. A. L. Allen, R. W. Anderson, R. M. McGill, and E。W. Powell, "Electrochemical Preparation of Uranium Tetrafluoride, Part I, Low Temperature Cell," K-680 (November 10, 1950).

4. R. W. Anderson, A. L. Allen, and E. W. Powell, "Electrochemical Preparation of Uranium Tetrafluoride, Part II, High Temperature Cell," K-681 (December 22, 1950)。

5. E. Lof thouse, "Dekyl Fluoride - Miscellaneous Notes, Note No. 28, "The Production of $\mathrm{DF}_{4}$ from $\mathrm{DF}_{6}$ by Electrolytic Reduction," Imperial Chemical Industries, Limited, General Chemical Group - Research Department, Widnes Laboratory, Widnes, BR-200 (July 6, 1953).

6. E. Lof thouse, "Dekyl Fluoride - Miscellaneous Notes, Note No. 27, Production of Dekanous Sulfate by Electrolytic Reduction," Imperial Chemical Industries, R/GC/986/27 (March 31, 1943).

7. E. Lof thouse, "The Manufacture of Uranium Tetrafluoride by the Wet Way Process," Imperial Chemical Industries, n.d., ARRE $\mathrm{X} / \mathrm{R}-249$.

8. J. A. Marinsky, "Development of the Excer Process II," ORNL-1979 (April 17, 1956).

9. D. A. Ellis, R. S. Long, and J. E. Magner, "New Methods for the Production of High-Purity Uranium Salts," DOW-159 (August 1, 1957).

10. K. B. Brown, C. F. Coleman, D. J. Crouse, J. O. Denis, and J. G. Moore, "The Use of Amines as Extractants for Uranium from Acidic Sulfate Liquors - A Preliminary Report," ORNL-1734 (May 27, 1954): 
11. J. G. Moore, K. B. Brown, and C. F. Coleman, "Further Studies of Amines as Extractants for Uranium from Acid Sulfate Solutions," ORNL_1922 (June 24, 1955).

12. D. J. Crouse and K. B. Brown, "Amine Extraction Processes for Uranium Recovery from Sulfate Liquors, Volume I," QRNL-1959 (September 30, 1955).

13. D. J. Crouse, K. B. Brown, W. D. Arnold, J. G. Moore, and R. S. Lowrie, "Uranium Extraction with Organonitrogen Compounds," ORNI_-2099 (May 14, 1956).

14. A. Pruess and J. Saunders, "The Solvent-Solvent Extraction of Uranium from Sulfuric Acld Solutions with Oil Soluble Amines," BMO-2533 (April 14, 1955).

15. H. G. Petrow, 0. A. Nietzel, J. C. Apidianakis, R. W. Lindstrom, and C. F. Lubinger, "Techniques for the Evaluation of Amines as Uranium Extractants and Properties of Some Satisfactory Amines," WIN-61 (August 26, 1957). 
Table 1

\section{Production of $\mathrm{UE}_{4} \cdot 3 / 4 \mathrm{H}_{2} \mathrm{O} \mathrm{by} \mathrm{SO}_{2}$ and $\mathrm{Cu}^{++}$}

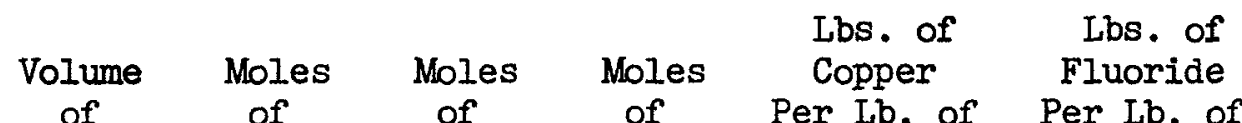

of of of of Per Lb. of Per Lb. of Hours Per Cent Tap Density

Run Solution Uranium Copper Fluoride $\mathrm{UE}_{4} \cdot 3 / 4 \mathrm{H}_{2} \mathrm{O} \mathrm{UE} \cdot 3 / 4 \mathrm{H}_{2} \mathrm{O}$ Run Recovery arams/ce

$\begin{array}{llllllllll}1 & 250 & 0.091 & 0.031 & 1.20 & 0.067 & 0.77 & 3 & 99.92 & 3.12 \\ 2 & 250 & 0.091 & 0.031 & 0.60 & 0.067 & 0.39 & 3 & 99.80 & 3.14 \\ 3 & 250 & 0.091 & 0.016 & 0.60 & 0.034 & 0.39 & 4 & 99.78 & 3.18 \\ 4 & 500 & 0.091 & 0.016 & 0.60 & 0.034 & 0.39 & 5 & 99.38 & 3.08 \\ 5 & 500 & 0.109 & 0.016 & 0.68 & 0.031 & 0.43 & 6 & 93.63 & 3.17 \\ 6 & 500 & 0.109 & 0.016 & 0.75 & 0.029 & 0.40 & 7 & 99.78 & 3.06 \\ 7 & 250 & 0.091 & 0.016 & 0.45 & 0.038 & 0.32 & 7 & 93.16 & 3.38\end{array}$

Assay of Green Salt from Run 4: \% Uranium $=72.8$

\% Fluoride $=23.1$

\% Water $=4.0$

$\mathrm{PPM} \mathrm{SO}_{4}=<50$

PPM Copper $=<50$

$\% \mathrm{UO}_{2}=$ nil

\% $\mathrm{UO}_{2} \mathrm{~F}_{2}=<0.1$ 
Table 2

\section{Recovery with Increasing $\mathrm{U}_{3} \mathrm{O}_{8}$ Concentration}

\begin{tabular}{|c|c|c|c|c|c|c|c|c|}
\hline Run & $\begin{array}{l}\text { Grams } \mathrm{U}_{3} \mathrm{O}_{8} \\
\text { Per Iiter }\end{array}$ & $\begin{array}{c}\text { Moles } \\
\text { of Uranium } \\
\text { Per } 500 \mathrm{ml}\end{array}$ & $\begin{array}{c}\text { Moles } \\
\text { of Copper } \\
\text { Per } 500 \mathrm{ml}\end{array}$ & $\begin{array}{l}\text { Moles } \\
\text { of Fluoride } \\
\text { Per } 500 \text { ml }\end{array}$ & $\begin{array}{c}\text { Moles of } \\
\text { Copper } \\
\text { Per Mole } \\
\text { of Uranium }\end{array}$ & $\begin{array}{l}\text { Moles of } \\
\text { Fluoride } \\
\text { Per Mole } \\
\text { of Uranium }\end{array}$ & $\begin{array}{l}\text { Per Cent } \\
\text { Recovery }\end{array}$ & $\begin{array}{c}\text { Tap } \\
\text { Density }\end{array}$ \\
\hline $\begin{array}{l}1 \\
2 \\
3 \\
4 \\
5 \\
6\end{array}$ & $\begin{array}{c}60.0 \\
61.7 \\
71.7 \\
100 \\
140 \\
200\end{array}$ & $\begin{array}{l}0.107 \\
0.110 \\
0.127 \\
0.178 \\
0.249 \\
0.357\end{array}$ & $\begin{array}{l}0.020 \\
0.020 \\
0.023 \\
0.032 \\
0.046 \\
0.064\end{array}$ & $\begin{array}{l}0.81 \\
0.84 \\
0.90 \\
1.20 \\
1.35 \\
1.80\end{array}$ & $\begin{array}{l}0.188 \\
0.182 \\
0.181 \\
0.180 \\
0.185 \\
0.180\end{array}$ & $\begin{array}{l}7.45 \\
7.65 \\
7.08 \\
6.75 \\
5.42 \\
5.05\end{array}$ & $\begin{array}{l}99.64 \\
99.58 \\
99.63 \\
99.81 \\
99.90 \\
99.95\end{array}$ & $\begin{array}{l}3.06 \\
3.06 \\
3.03 \\
3.08 \\
3.18 \\
2.75^{3}\end{array}$ \\
\hline
\end{tabular}

$1 /$ Green salt was determined to contain 24 PPM copper impurity.

2/Tap Density was considerably lower than normal due to a stirring failure.

Table 3

Effect of Stirring on Tap Density

Concentrations in moles per $500 \mathrm{ml}: \quad U=0.107, \mathrm{Cu}=0.02$, and $\mathrm{F}=0.81$

\begin{tabular}{|c|c|c|c|c|}
\hline Run & $\begin{array}{l}\text { Stirrer } \\
\text { Position }\end{array}$ & $\begin{array}{l}\text { Stirrer } \\
\text { Speed }\end{array}$ & \% Recovery & $\begin{array}{l}\text { Tap Density } \\
\mathrm{UF}_{4} \cdot 3 / 4 \mathrm{H}_{2} \mathrm{O}\end{array}$ \\
\hline 1 & - & none & 99.70 & 2.40 \\
\hline 2 & low & slow & 99.70 & 2.50 \\
\hline 3 & medium & slow & 99.78 & 2.80 \\
\hline 4 & medium & medium & 99.60 & 3.05 \\
\hline 5 & medium & fast & 99.82 & 3.05 \\
\hline
\end{tabular}


Table 4

Large Scale Production of $\mathrm{UF}_{4} \cdot 3 / 4 \mathrm{H}_{2} \mathrm{O}$

Temperature: $93^{\circ} \mathrm{C}$ to $95^{\circ} \mathrm{C}$

\begin{tabular}{|c|c|c|c|c|c|c|c|c|c|c|c|c|c|c|}
\hline \multirow[b]{2}{*}{ Run } & \multirow{2}{*}{$\begin{array}{l}\text { Volume } \\
\text { in } \\
\text { Lizers }\end{array}$} & \multicolumn{6}{|c|}{$\begin{array}{l}\text { Composition of Feed } \\
\text { in } \\
\text { woles Per iiter }\end{array}$} & \multirow{2}{*}{$\begin{array}{l}\text { Lbs, of } \mathrm{Cu}^{++} \\
\text {Per Lb. } \\
\mathrm{UF}_{4} \cdot 3 / 4 \mathrm{H}_{2} \mathrm{O}\end{array}$} & \multirow{2}{*}{$\begin{array}{l}\text { Lbs, of } F^{-} \\
\text {Per } \mathrm{Lb}^{-} \\
\mathrm{UF}_{4} \cdot 3 / 4 \mathrm{H}_{2} \mathrm{O}\end{array}$} & \multirow{2}{*}{$\begin{array}{l}\text { Lbs. of } \mathrm{SO}_{2} \\
\mathrm{Per} \mathrm{Lb} \\
\mathrm{UF}_{4} \cdot 3 / 4 \mathrm{H}_{2} \mathrm{O}\end{array}$} & \multirow{2}{*}{$\begin{array}{l}\text { Reaction } \\
\text { Time } \\
\text { (hours) }\end{array}$} & \multirow{2}{*}{$\begin{array}{l}\text { Per Cent } \\
\text { Recovery }\end{array}$} & \multirow{2}{*}{$\begin{array}{l}\text { Tap } \\
\text { Density } \\
\text { g/cc }\end{array}$} & \multirow{2}{*}{$\begin{array}{l}\text { Lbs. of } \\
\mathrm{UF}_{4} \cdot 3 / 4 \text { H2O } \\
\text { Produced } \\
\text { in Run }\end{array}$} \\
\hline & & $U$ & $\mathrm{Cu}^{++}$ & $\mathrm{F}^{-}$ & $\mathrm{Cl}^{-}$ & $\mathrm{SO}_{4}=$ & $\mathrm{H}^{+} \underline{-1}$ & & & & & & & \\
\hline$\perp$ & $i .30$ & 6.204 & 0.030 & 1.52 & 0.55 & 0.76 & 3.25 & 0.036 & 0.43 & 0.49 & 6 & 99.46 & 3.17 & 0.92 \\
\hline 2 & 6.35 & 0.231 & 0.042 & 1.65 & 0.65 & 0.86 & 3.65 & 0.037 & 0.41 & 0.71 & 6 & 99.69 & 3.17 & 1.03 \\
\hline 3 & 6.35 & 0.231 & 0.042 & 1.65 & 0.65 & 0.86 & 3.65 & 0.037 & 0.41 & 0.47 & 6 & 99.16 & 3.27 & 1.03 \\
\hline 4 & $\because .60$ & 0.400 & 0.014 & 2.23 & 0.80 & 0.87 & 4.23 & 0.036 & 0.33 & 0.49 & 6 & $92.35^{2} /$ & 3.01 & 2.01 \\
\hline 5 & 8.50 & 0.204 & 0.038 & 1.77 & 0.84 & 0.78 & 3.77 & 0.036 & 0.51 & 0.29 & 5 & 99.57 & 3.00 & 1.24 \\
\hline$E$ & 1.85 & 0.635 & 0.119 & 3.25 & 0.89 & 0.89 & 5.25 & 0.036 & 0.30 & 0.28 & 7 & 99.92 & $2.90^{9} /$ & 3.60 \\
\hline i & 6.55 & 0.453 & 0.086 & 2.52 & 0.91 & 0.91 & 4.52 & 0.036 & 0.32 & 0.37 & 6 & 99.92 & 3.02 & 2.02 \\
\hline 8 & 40.0 & 0.453 & 0.086 & 2.52 & 0.91 & 0.91 & 4.52 & 0.036 & 0.32 & 0.29 & 6 & 99.91 & 3.17 & 12.7 \\
\hline 9 & 40.0 & 0.453 & 0.086 & 2.52 & 0.91 & 0.91 & 4.52 & 0.036 & 0.32 & 0.29 & 6 & 99.87 & 3.08 & 12.7 \\
\hline 10 & 40.0 & 0.453 & 0.086 & 2.52 & 0.91 & 0.91 & 4.52 & 0.036 & 0.32 & 0.29 & 6 & 99.90 & 3.11 & 12.7 \\
\hline
\end{tabular}

$1 /$ Feed solutions contain approximately $2 \mathrm{H}$ of $\mathrm{H}^{+}$. The additional $\mathrm{H}^{+}$ concentration is due to the addition of $\mathrm{HF}$.

$2 /$ Low Recovery is due to a low fluoride excess.

$3 /$ Low Density occurred because of a heat transfer problem. 
Table 5

Dry Screen Analysis of UE $\cdot 3 / 4 \mathrm{H}_{2} \mathrm{O}$, Per Cent Retained on Screen

\begin{tabular}{|c|c|c|c|c|c|c|c|}
\hline \multirow[b]{2}{*}{ Sample } & \multirow{2}{*}{$\begin{array}{c}\text { Tap } \\
\text { Density }\end{array}$} & \multicolumn{6}{|c|}{ Screen Number } \\
\hline & & +200 & +250 & +270 & +325 & +400 & 400 or $\mathrm{Pan}$ \\
\hline 1 & 2.75 & Trace & Trace & 2.7 & 21.9 & 28.6 & 46.8 \\
\hline 2 & 3.01 & Trace & Trace & 0.2 & 19.9 & 38.4 & 41.5 \\
\hline 3 & 3.01 & Trace & Trace & 4.4 & 39.6 & 15.4 & 40.6 \\
\hline 4 & 3.17 & Trace & 0.3 & 0.6 & 15.8 & 16.8 & 66.5 \\
\hline 5 & 3.22 & Trace & 0.5 & 1.9 & 22.8 & 30.4 & 44.4 \\
\hline 6 & 3.45 & 0.2 & 0.3 & 2.1 & 17.1 & 24.1 & 56.2 \\
\hline
\end{tabular}




\section{Table 6}

Chemical and Spectrographic Analysis of UF $\cdot 3 / 4 \mathrm{H}_{2} \mathrm{O}$

\section{Chemical Analysis}

$\begin{array}{lrll}\text { Total U, } \% & 72.38 & \text { LOI }\left(110^{\circ} \mathrm{C}\right), \% & 0.58 \\ \mathrm{U}^{+4}, \phi & 72.66 & \text { Apparent Density, g/cc } & 2.50 \\ \mathrm{UO}_{2}, \phi & <0.05 & \text { Tap Density, g/cc } & 3.15\end{array}$

Spectrographic Analysis - PPM on U Basis

$\begin{array}{lll}\mathrm{AI}<4 & \mathrm{Gd}<0.02 & \mathrm{~Pb}<1 \\ \mathrm{~B}<1 & \mathrm{Ho}<0.02 & \mathrm{~S} 80 \\ \mathrm{Ba}<1 & \mathrm{LI}<2.5 & \mathrm{Sm}<0.02 \\ \mathrm{Ca} \quad \mathrm{I2} & \mathrm{Ia}<0.02 & \mathrm{Sn}<1 \\ \mathrm{Cd}<0.02 & \mathrm{Mg}<1 & \mathrm{Sr}<1 \\ \mathrm{Cr}<10 & \mathrm{Mn}<4 & \mathrm{Th}<10 \\ \mathrm{Cu} \quad 40 & \mathrm{Mo}<4 & \mathrm{~V} \quad 20 \\ \mathrm{Dy}<0.02 & \mathrm{Na}<1 & \mathrm{Y} \quad 0.03 \\ \mathrm{Er}<0.02 & \mathrm{Ni} \quad 12 & \mathrm{Yb}<0.02 \\ \mathrm{Fe} \quad 13 & \mathrm{P} \quad 20 & \mathrm{Zn}<20\end{array}$




\section{Table 7}

\section{Decontamination of Uranium by UE Precipitation}

Concentrations (PPM) are on a uranium basis

$\begin{array}{lccr}\text { Element } & \begin{array}{c}\text { PPM Impurity } \\ \text { Feed Solution }\end{array} & \begin{array}{c}\text { PPM Impurity } \\ \text { UE. } 3 / 4 \text { H2O }\end{array} & \begin{array}{c}\text { Decontamination } \\ \text { Factors }\end{array} \\ \text { As } & 6,500 & 0.3 & 15,000 \\ \text { B } & 4,000 & <1 & >4,000 \\ \text { Cu } & 43,000 & 33 & 1,300 \\ \text { Mo } & 6,000 & 4 & 1,500 \\ \text { P } & 4,600 & 45 & 100 \\ \text { S } & 490,000 & 110 & 4,500 \\ \text { Si } & 2,000 & <20 & >100 \\ \text { Ti } & 20,000 & 20 & 1,000 \\ \text { V } & 11,700 & 4 & 2,900 \\ \text { Zr } & 20,000 & 200 & 100 \\ \text { Ce* } & 66,000 & 6 & 11,000\end{array}$

*This decontamination factor is for both solvent extraction and precipitation. 
WTN-90

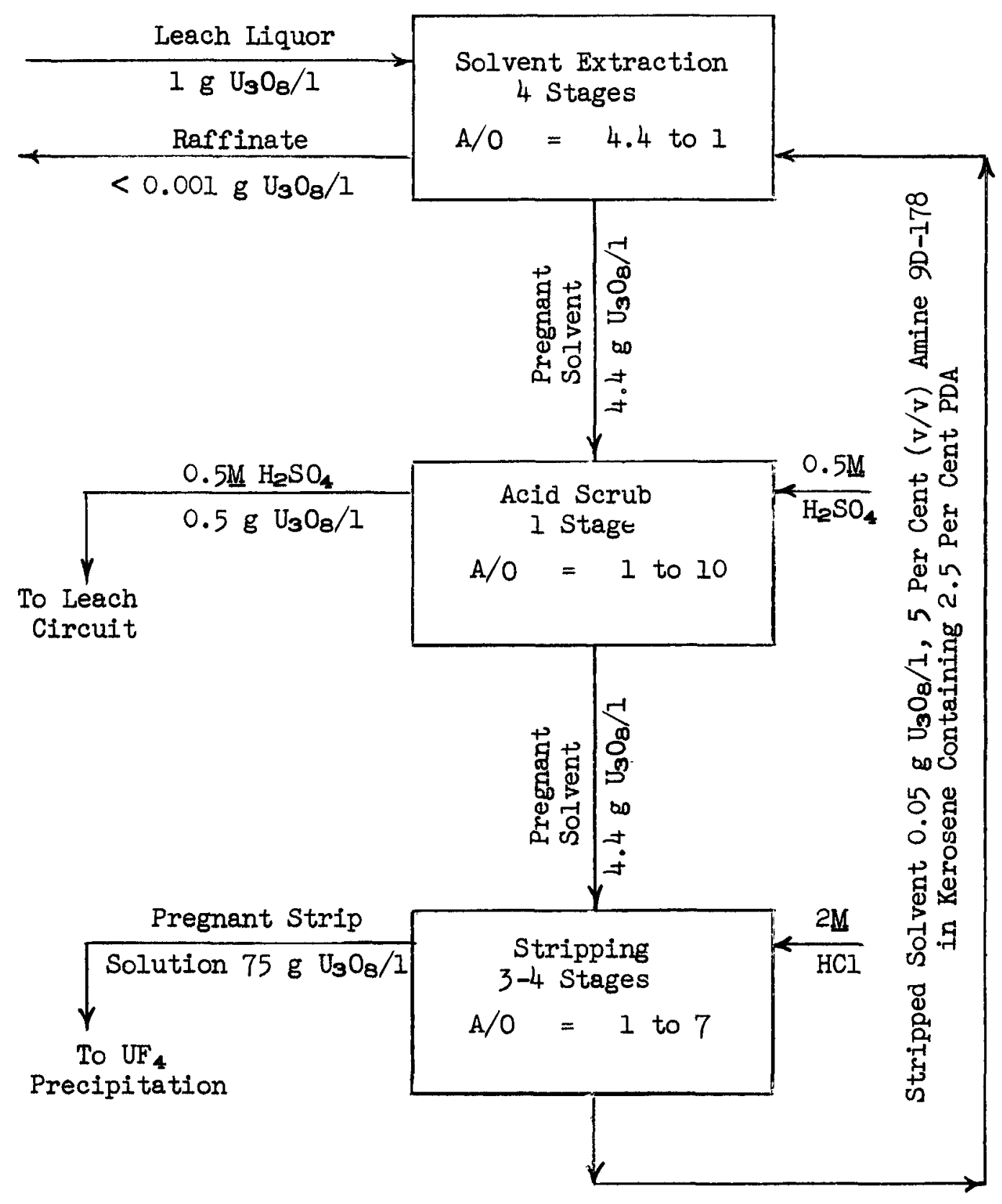

Fig. 1. Preparation of UF Precipitation Feed Solution by Secondary Amine Extraction - 2M HCI Strip 
WIN-90

- 42 -

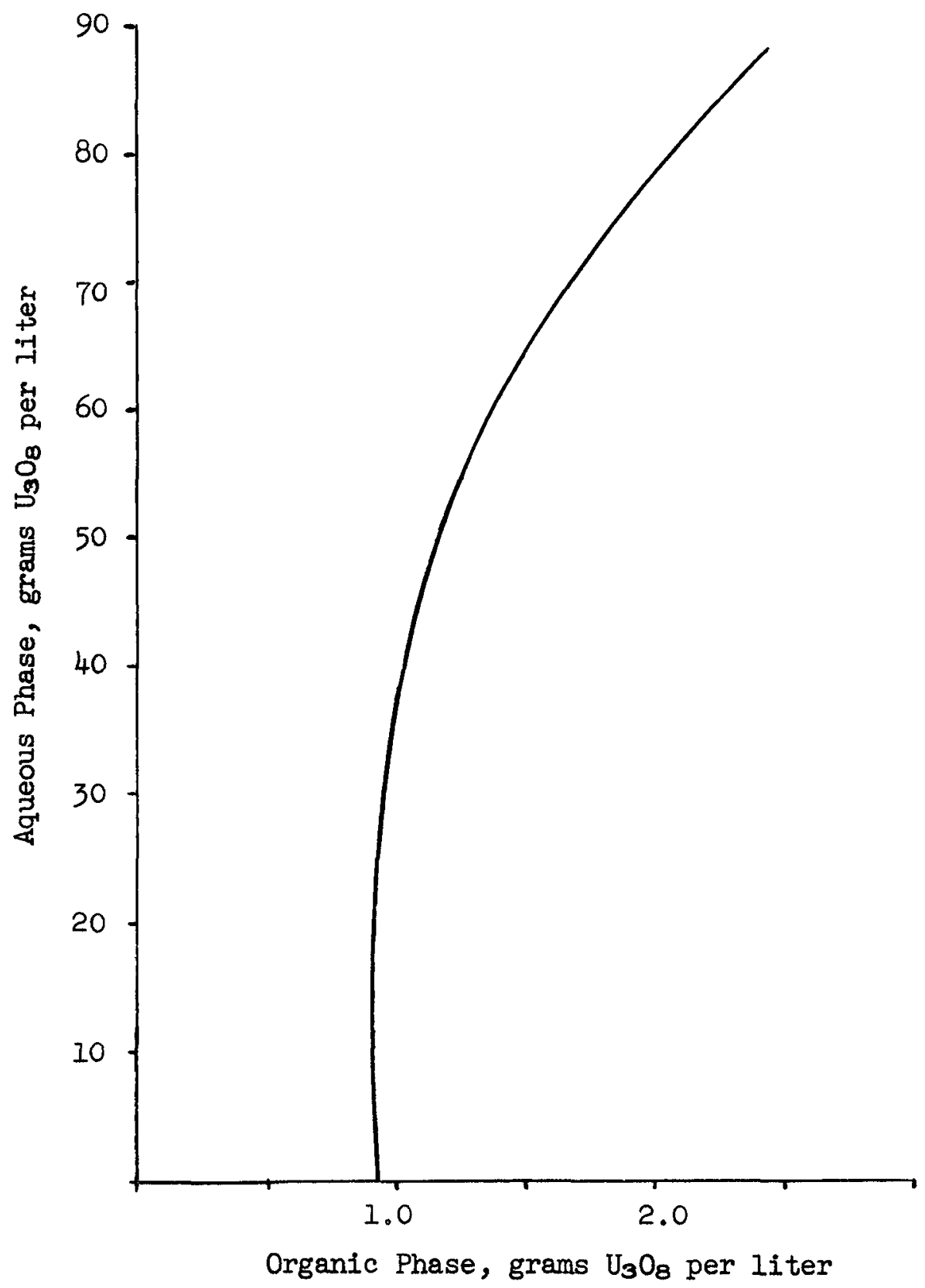

Fig. 2. Uranium Stripping Isotherm for 2M HCI - 0.3M Alamine System 


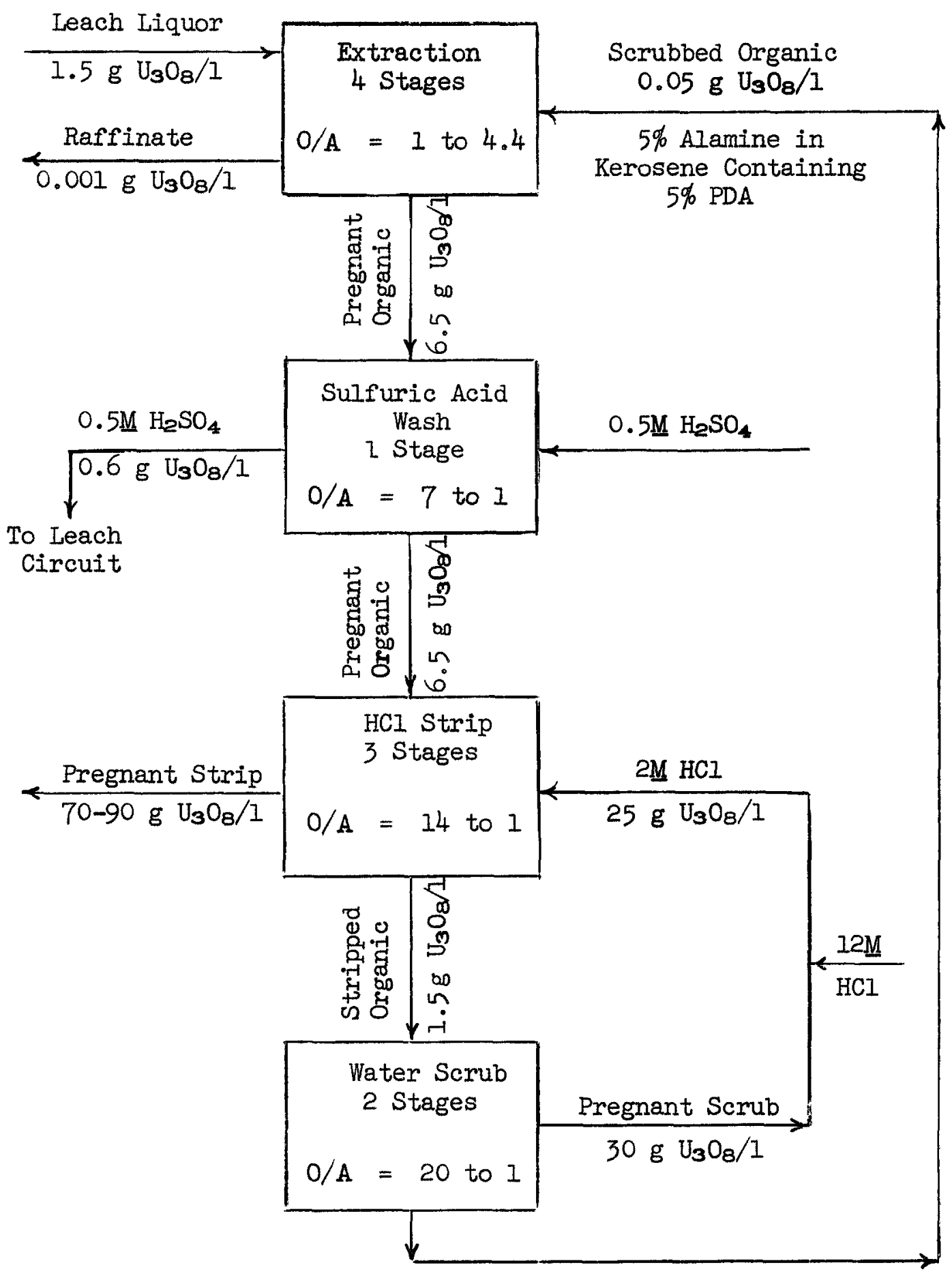

Fig. 3. Preparation of UE Precipitation Feed Solution by Tertiary Amine Extraction - 2M HCl Strip 
WIN-90

-44 -

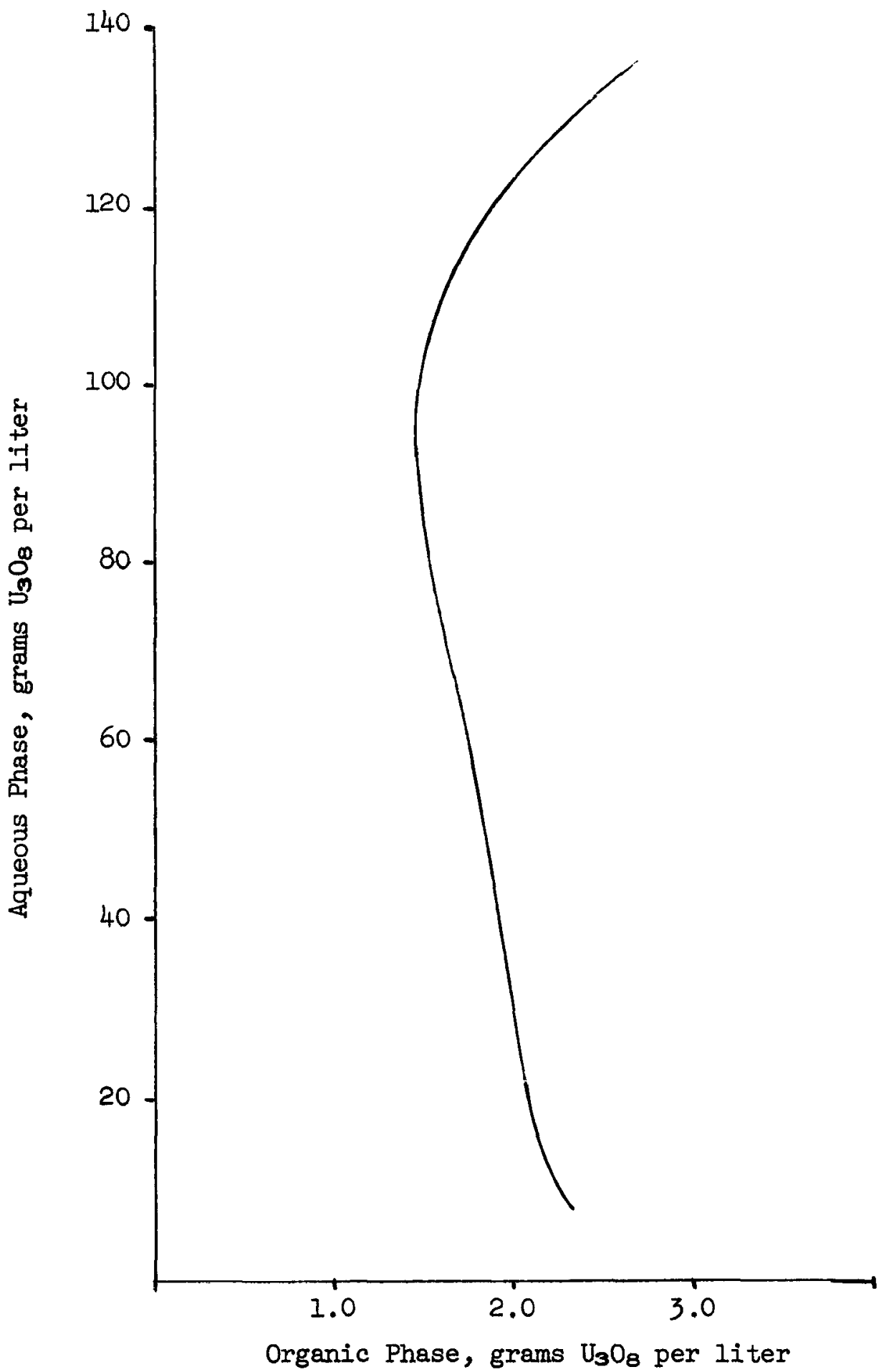

Fig. 4. Uranium Stripping Isotherm for 5\% Alamine-3M HCl System 
WIN-90

$-45-$

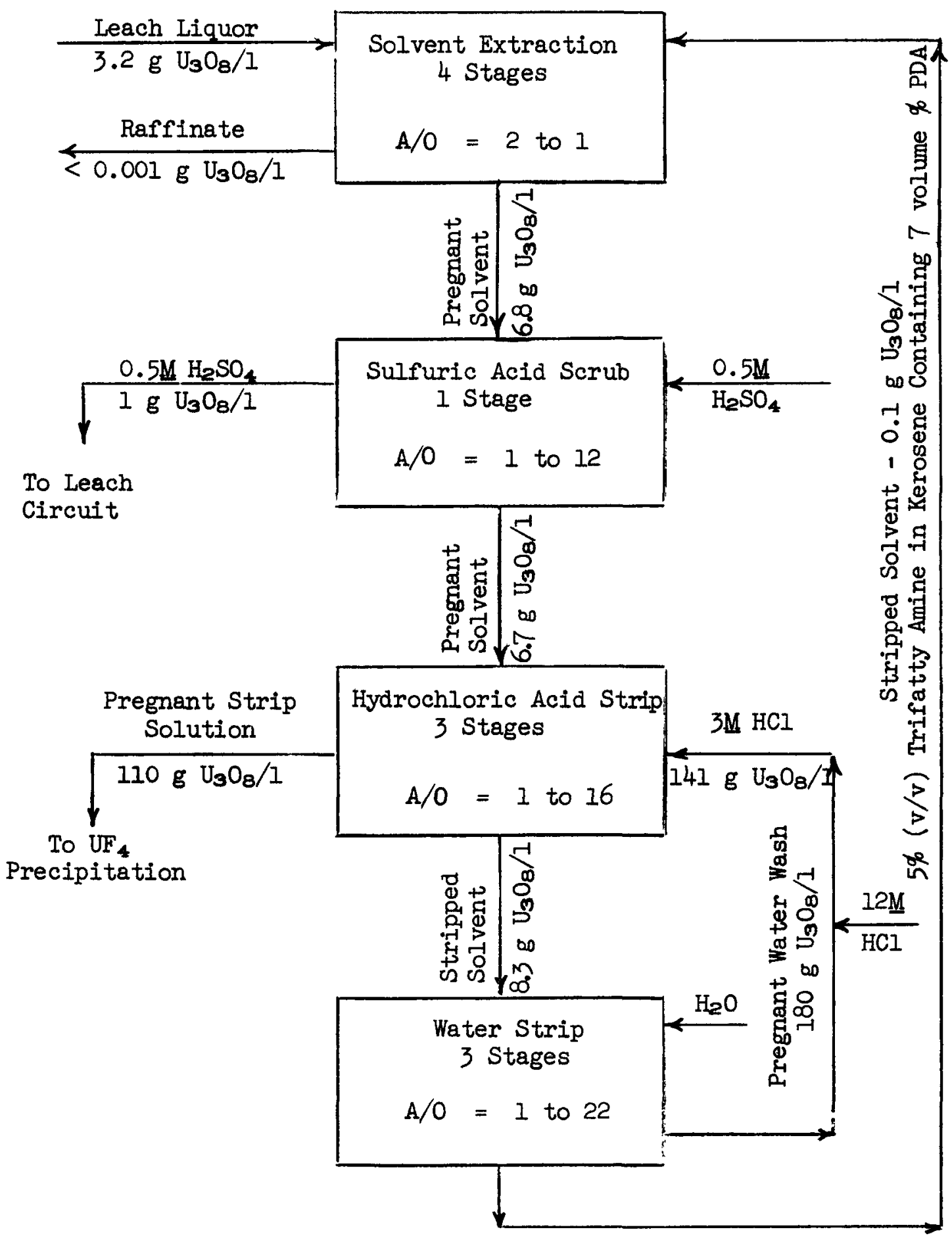

Fig. 5. Preparation of UE Precipitation Feed Solution by Tertiary Amine Extraction - 3M HCl Strip 


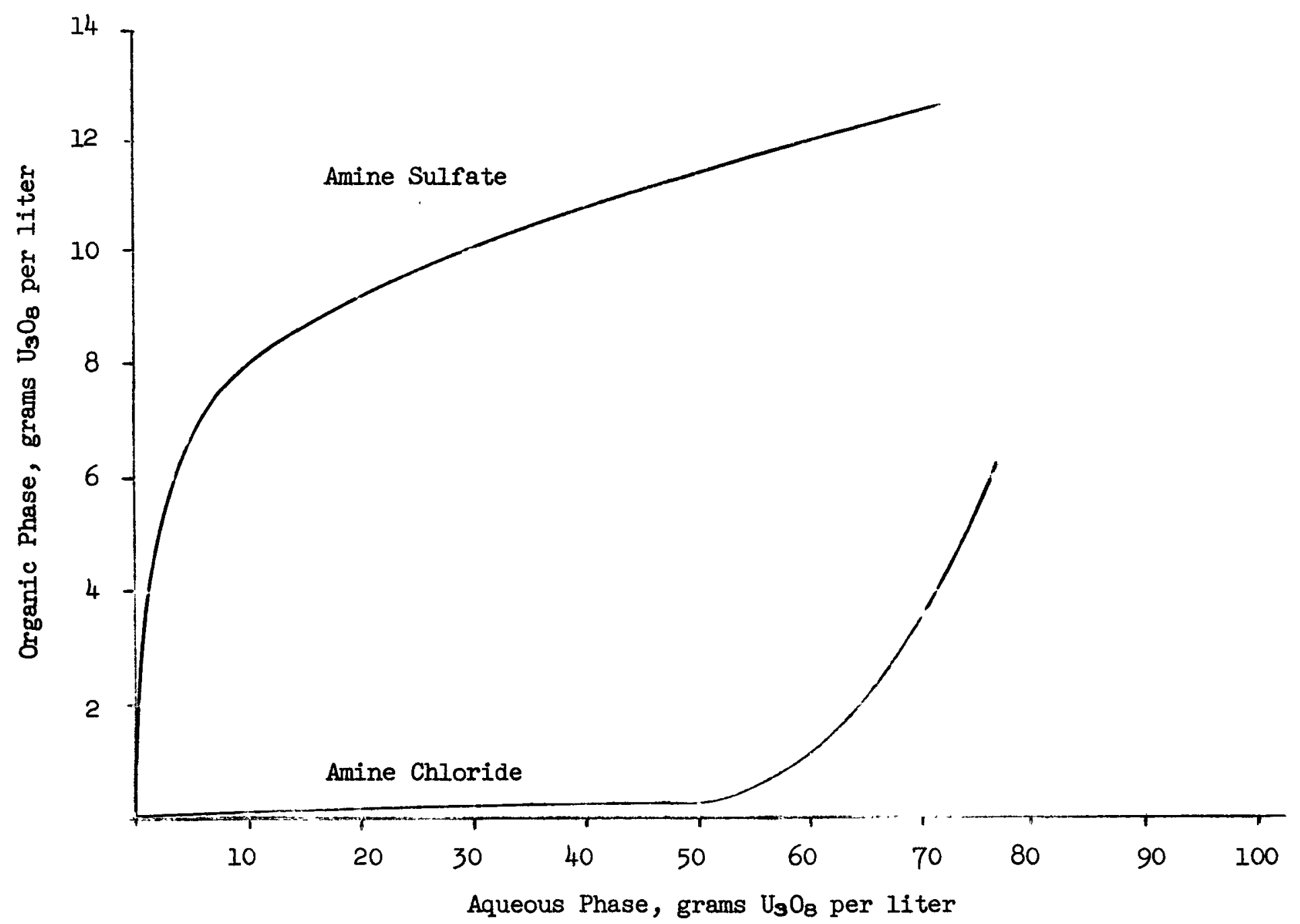

1
至悬
1

Fig. 6. Extraction Isotherms Using $10 \%$ Amine $9 D-178$ in Sulfate and Chloride Form 


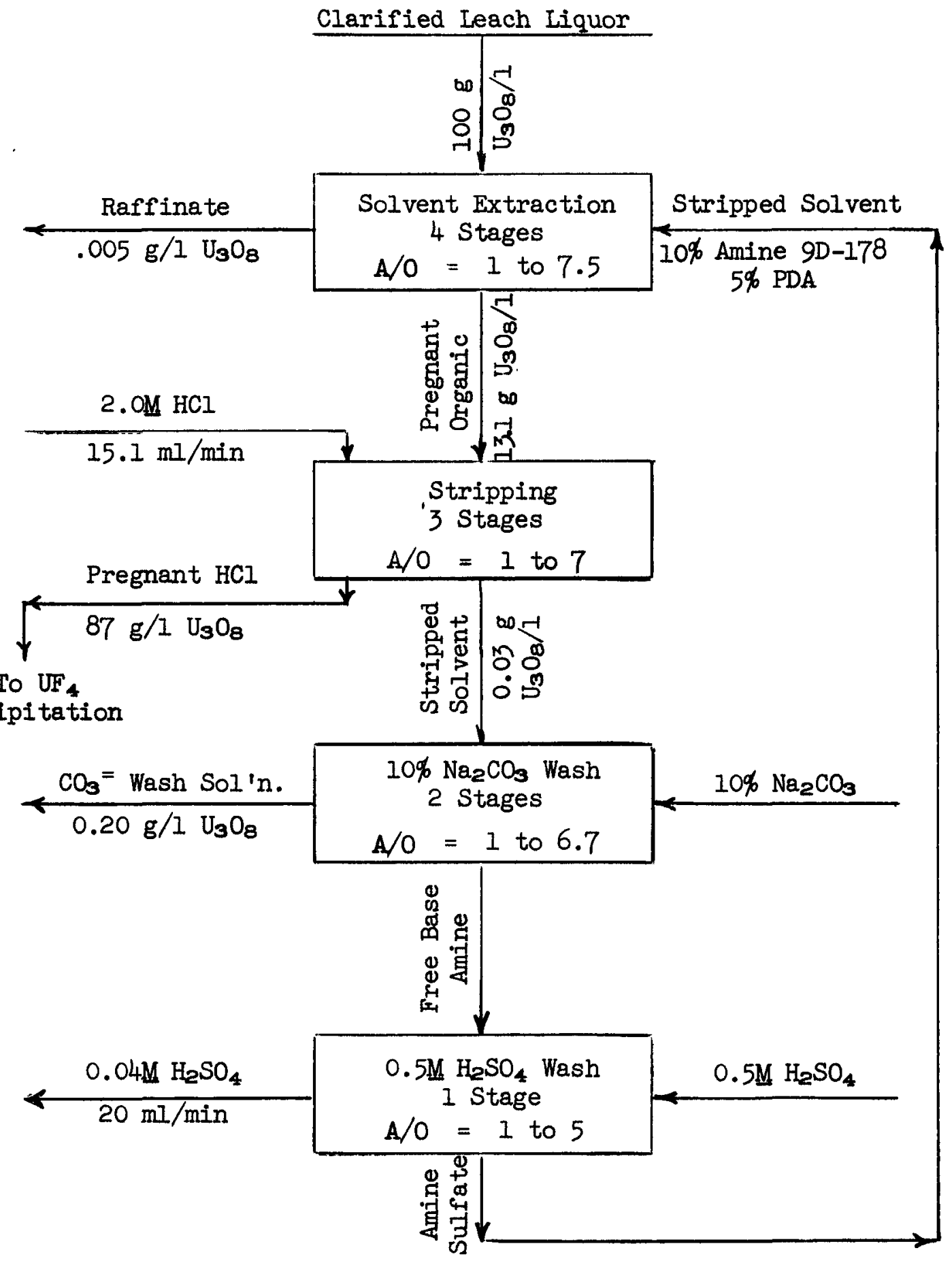

Fig. 7. Preparation of UF Precipitation Feed Solution from concentrate Dissolved in Sulfuric Acid by Secondary Amine Extraction - 2M HCI Strip 
WIN -90

-48 -

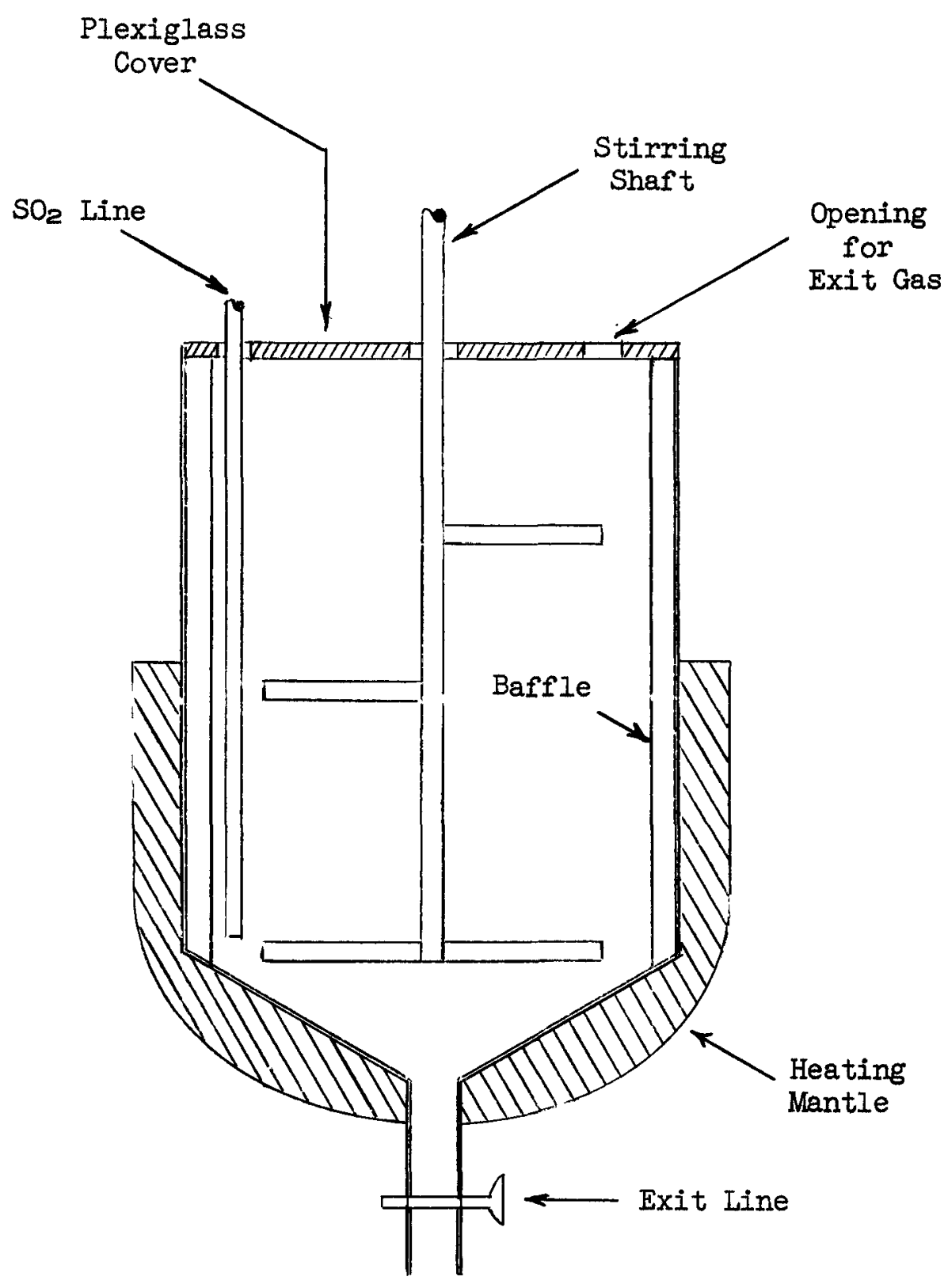

Fig. 8. Forty-Liter Reaction Vessel 


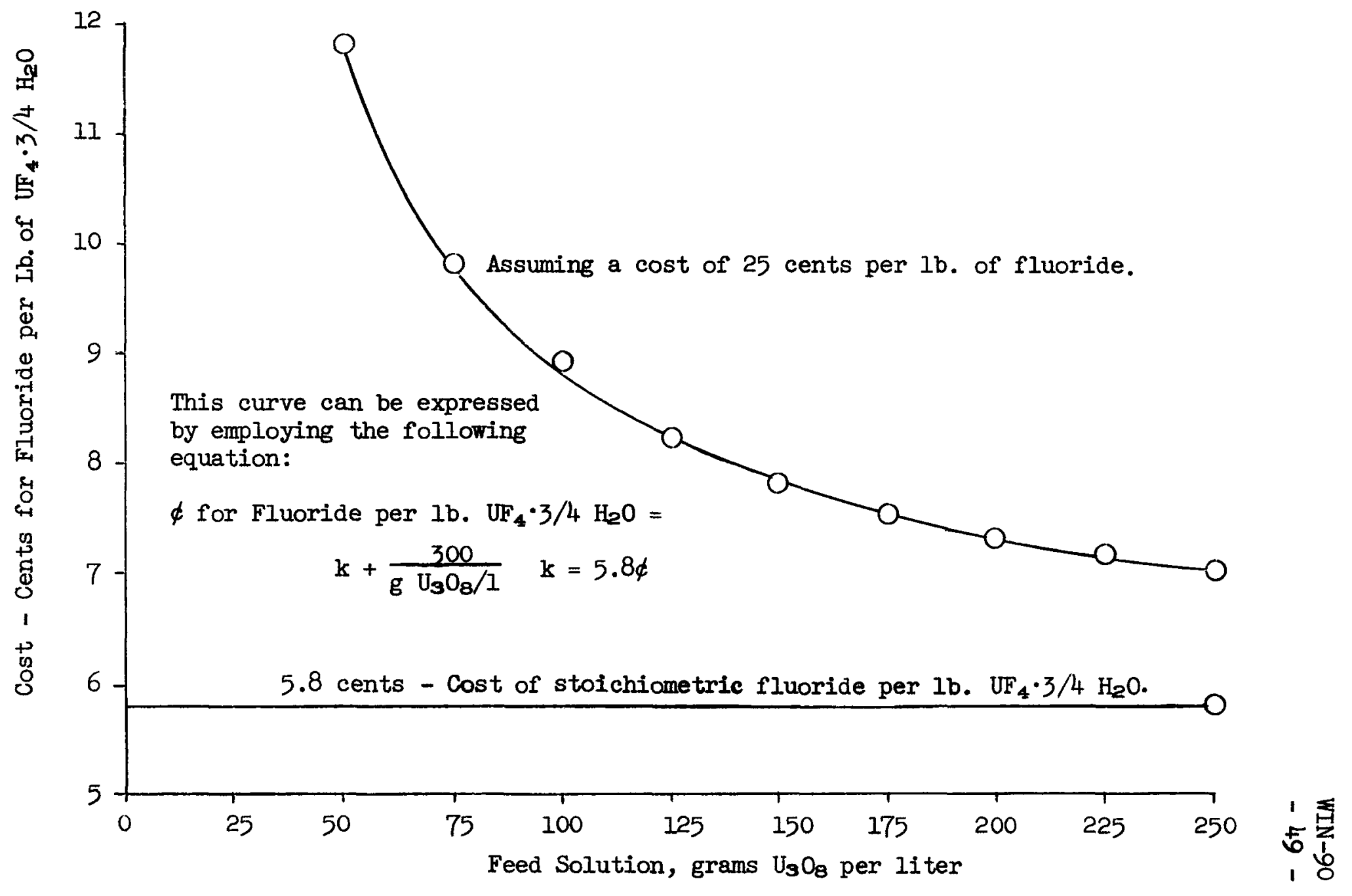

Fig. 9. Cost of Fluoride for Various Feed Solutions 


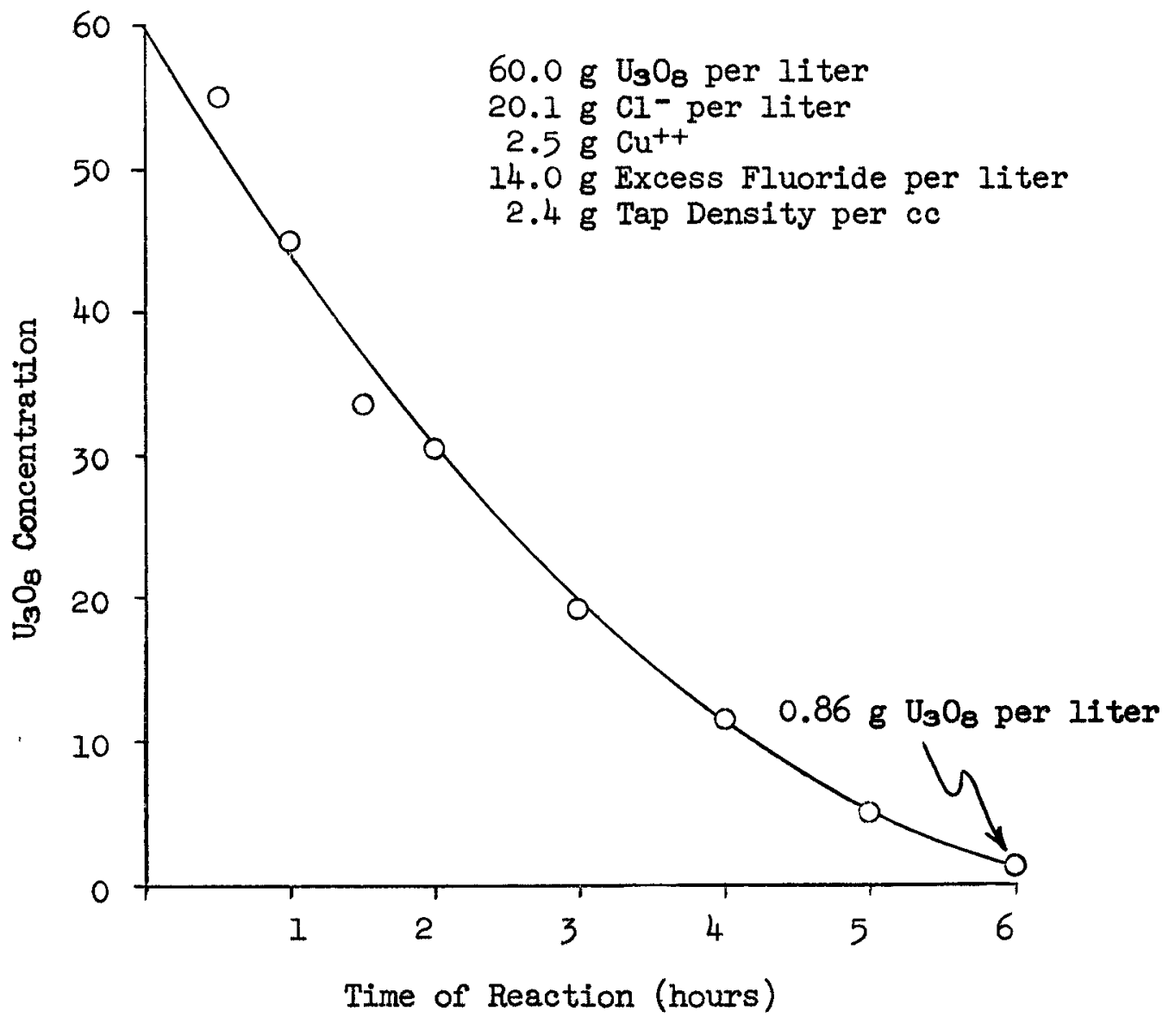

Fig. 10. Rate Curve at $73^{\circ} \mathrm{C}$ 
WIN-90

-51 -

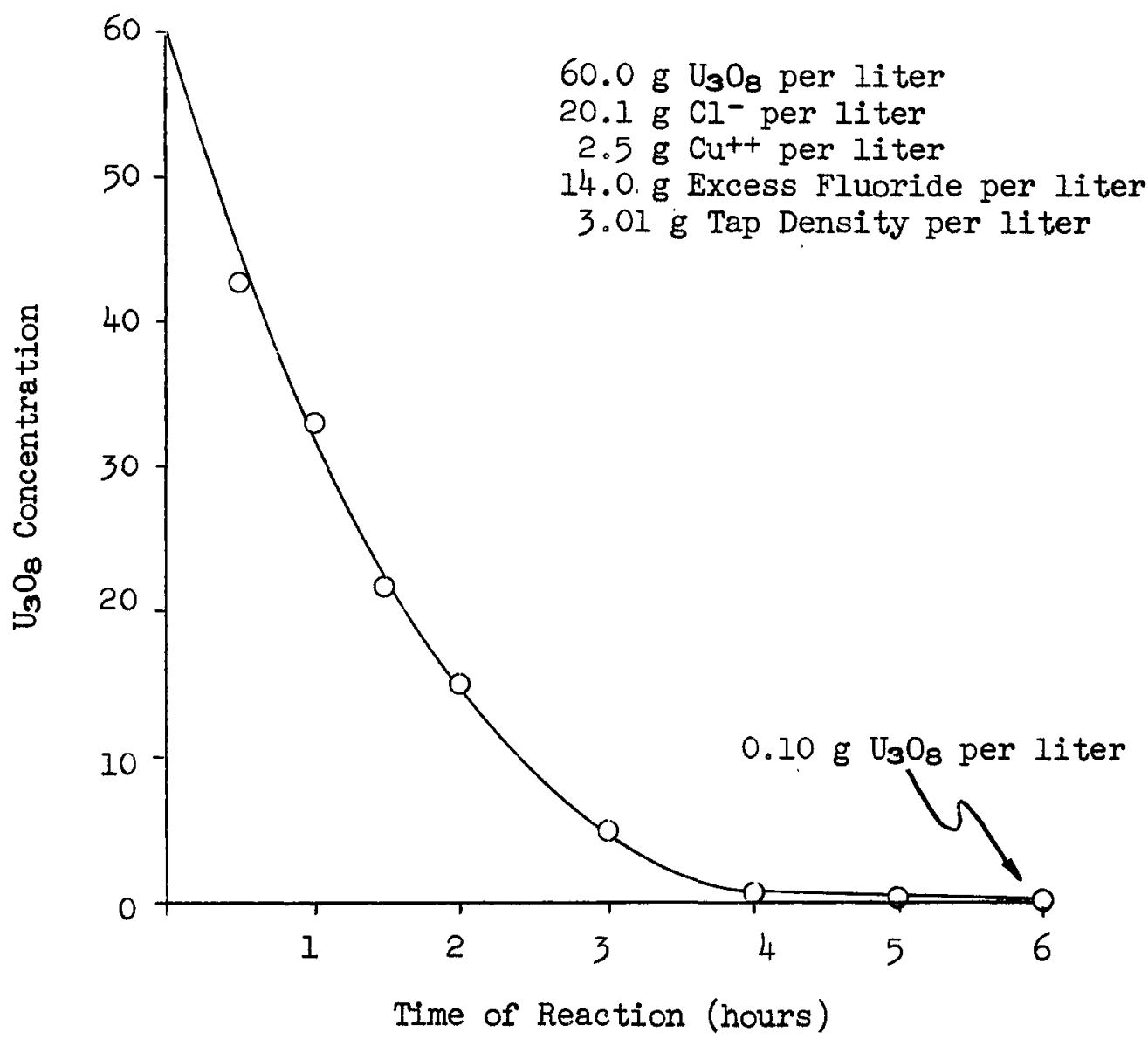

Fig. 11. Rate Curve at $83^{\circ} \mathrm{C}$ 


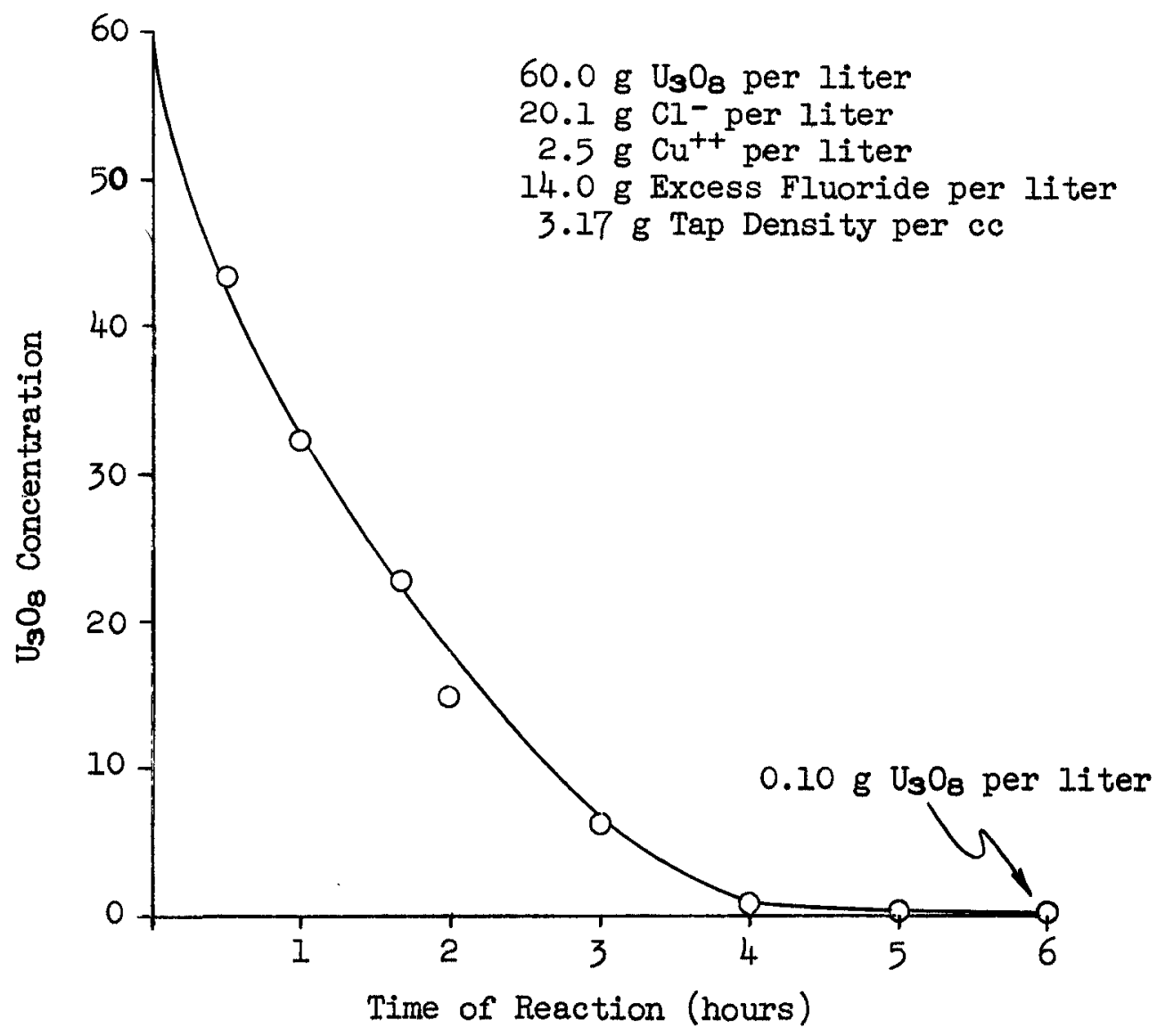

Fig. 12. Rate Curve at $93^{\circ} \mathrm{C}$ 
WIN-90

-53 -

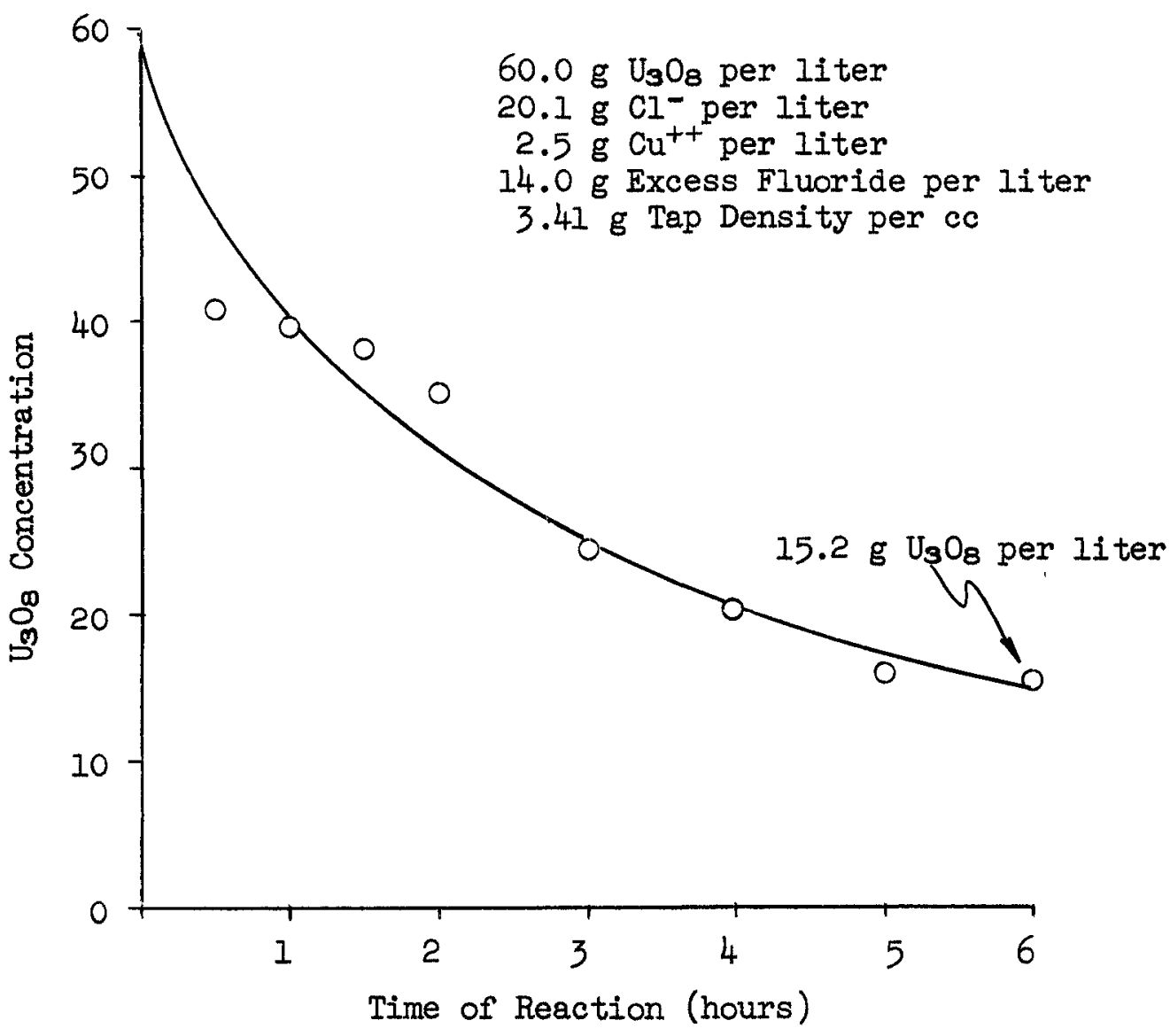

Fig. 13. Rate Curve at $103^{\circ} \mathrm{C}$ 


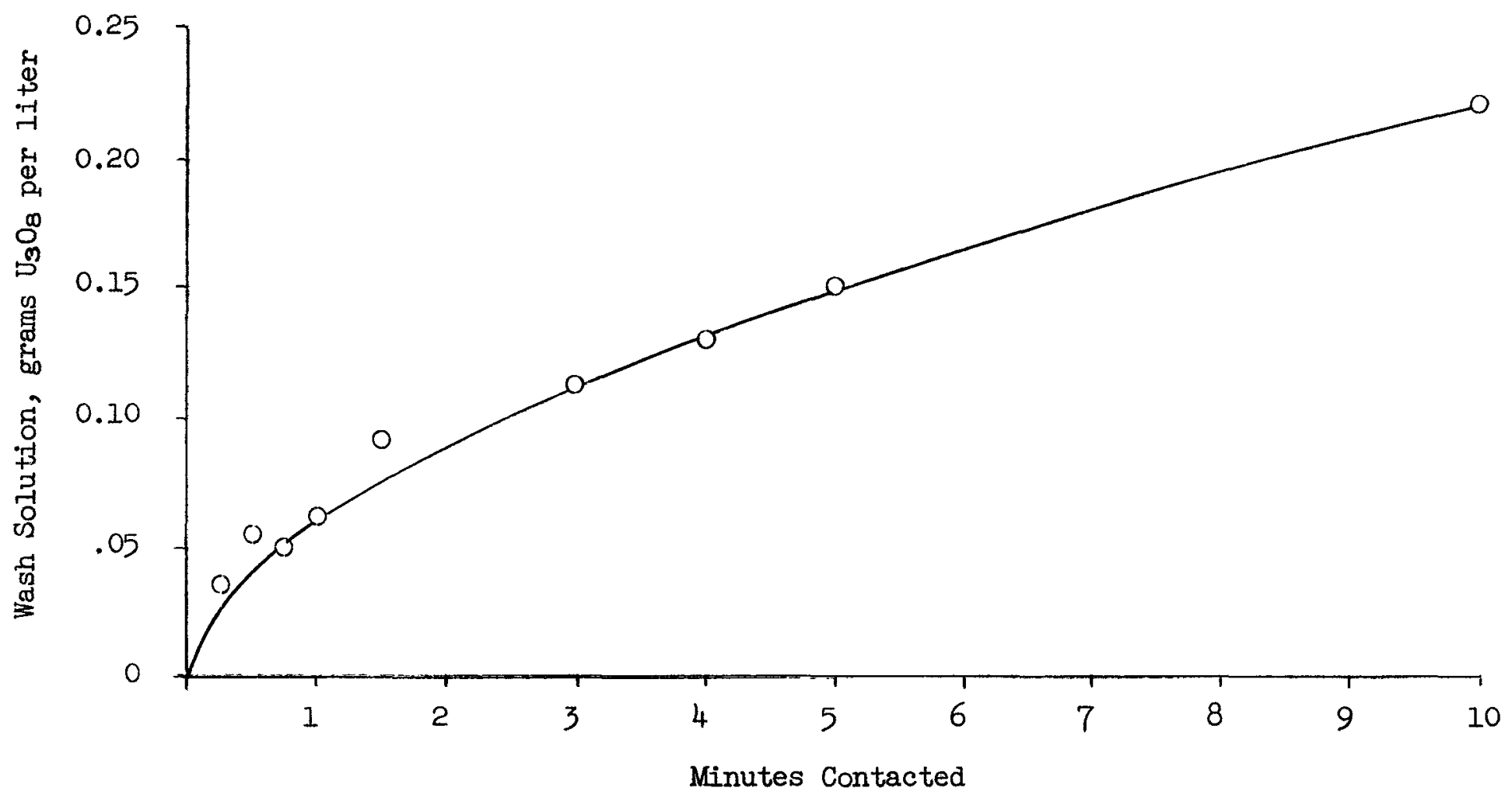

Fig. 14. Solubility of $\mathrm{UF}_{4} \cdot 3 / 4 \mathrm{H} 20$ As A Function of Contact Time 


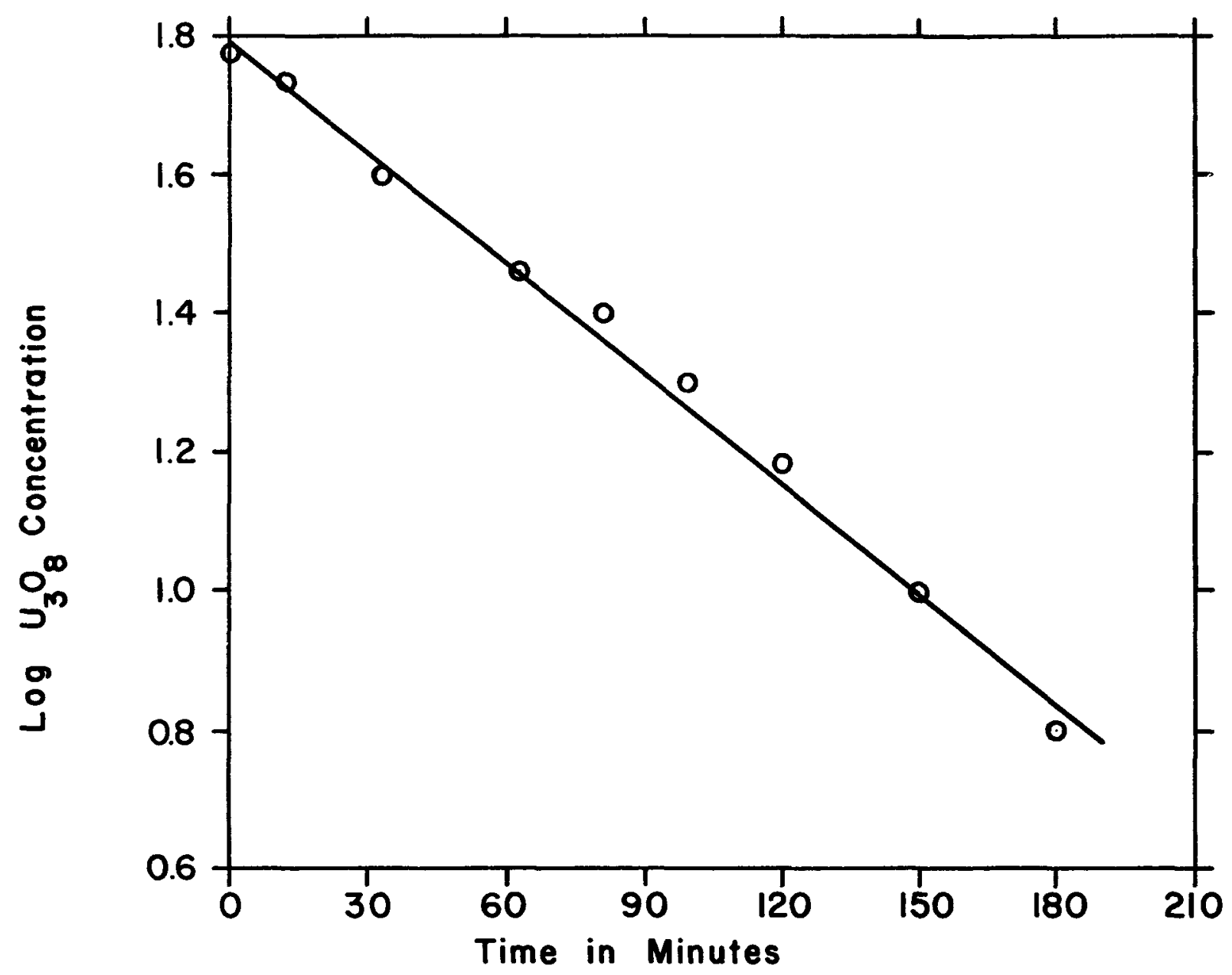

LOG $\left(U_{3} O_{8}\right)$ VS TIME, INDICATING FIRST ORDER DEPENDENCY FOR URANIUM 


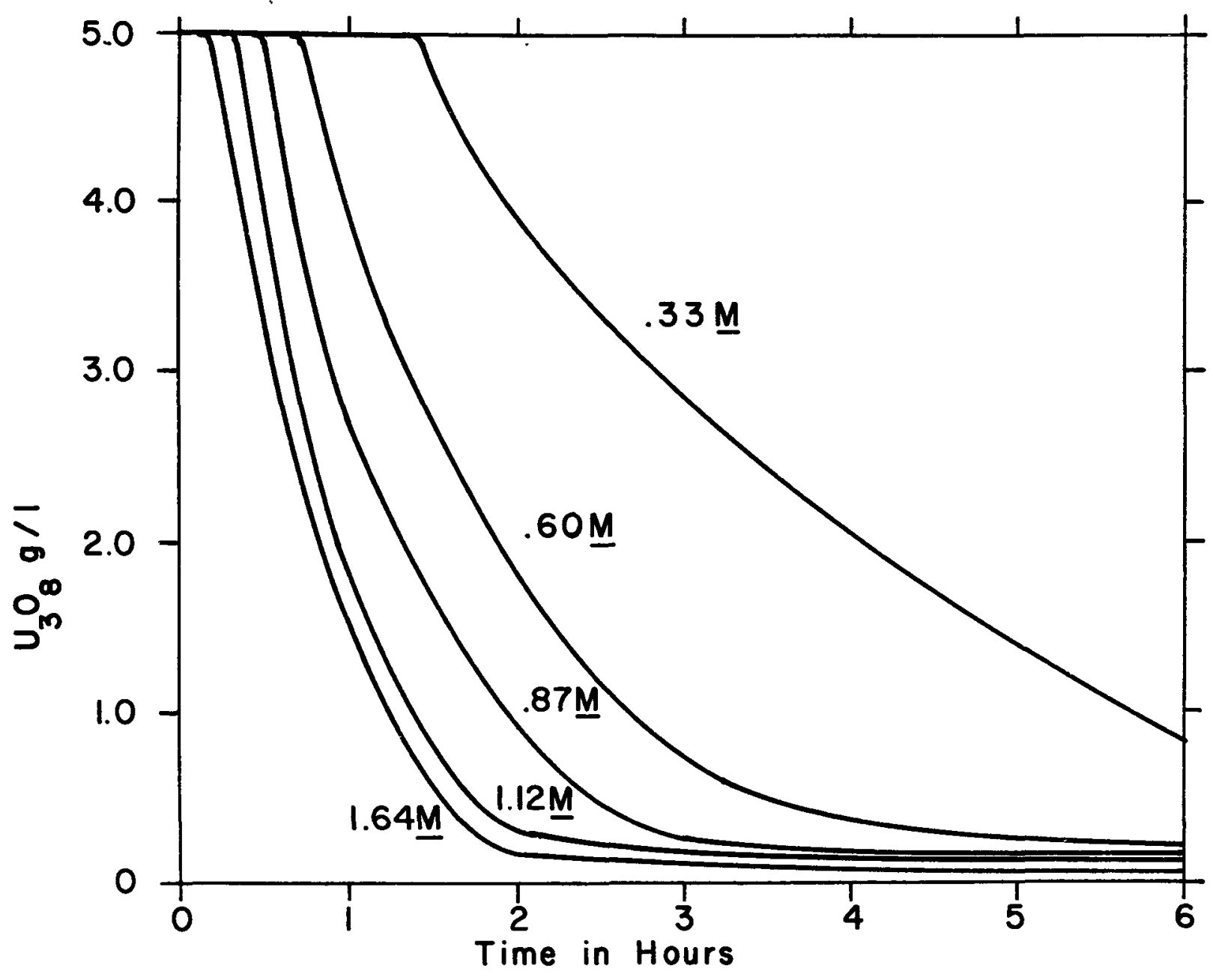

EFFECT OF FLUORIDE CONCENTRATION ON THE RATE OF PRECIPITATION OF UF $_{4}$

FIGURE 16 


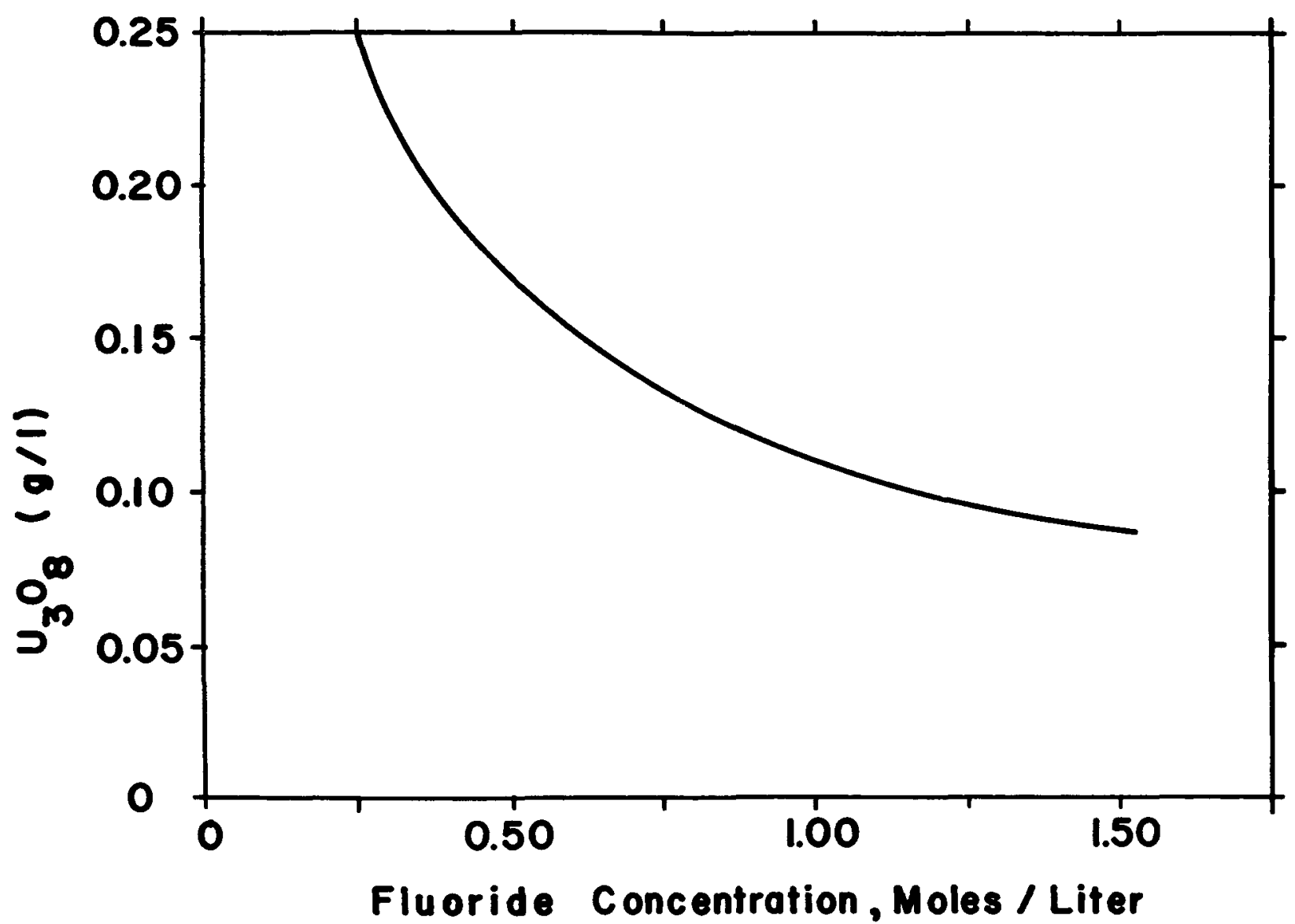

EFFECT OF FLUORIDE CONCENTRATION ON THE SOLUBILITY OF UF $_{4}$ 


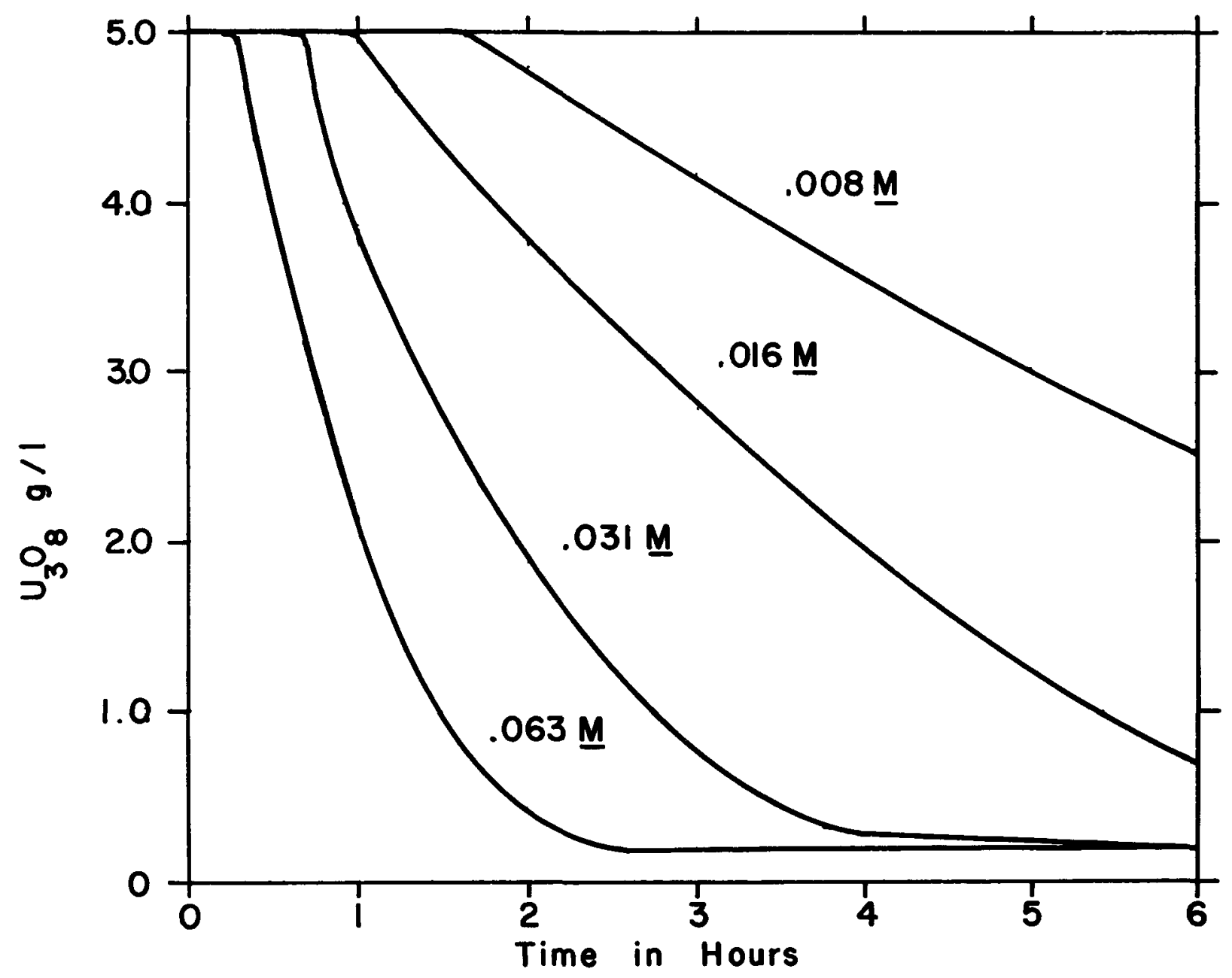

EFFECT OF COPPER CONCENTRATION ON THE RATE OF PRECIPITATION OF UF

FIGURE 18 


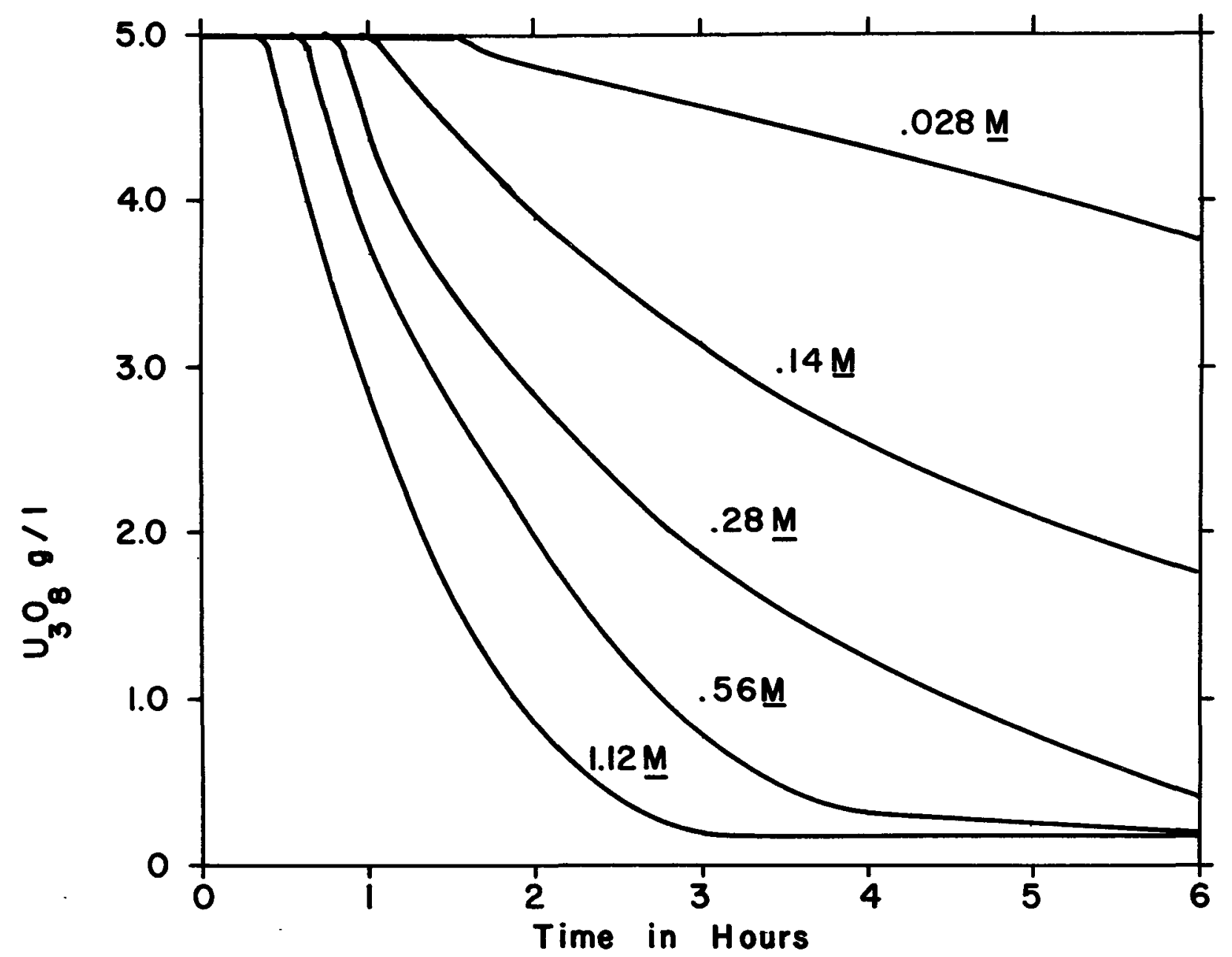

EFFECT OF CHLORIDE CONCENTRATION ON THE RATE OF PRECIPITATION OF UF $_{4}$ 


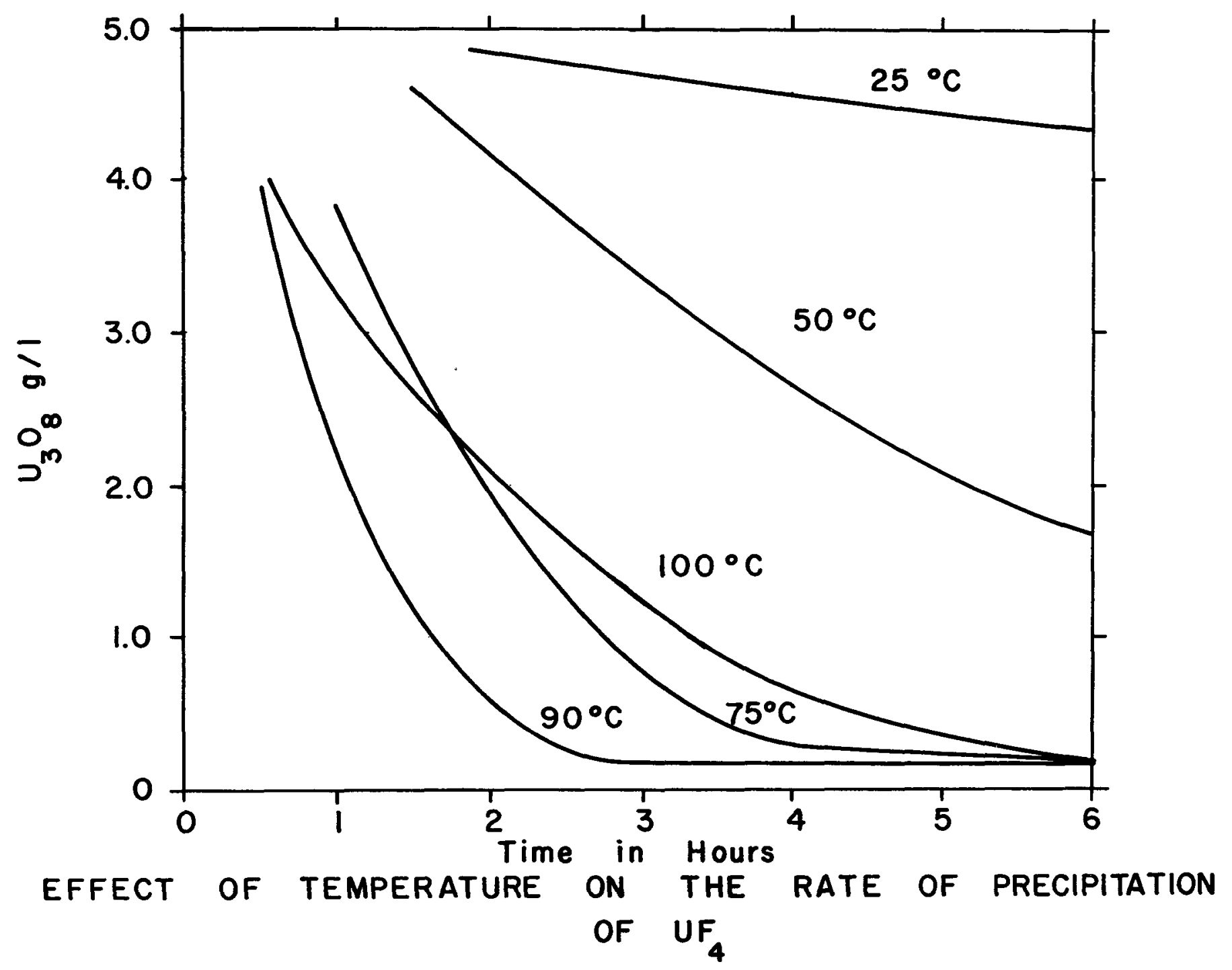

1 是
잉

FIGURE 20 


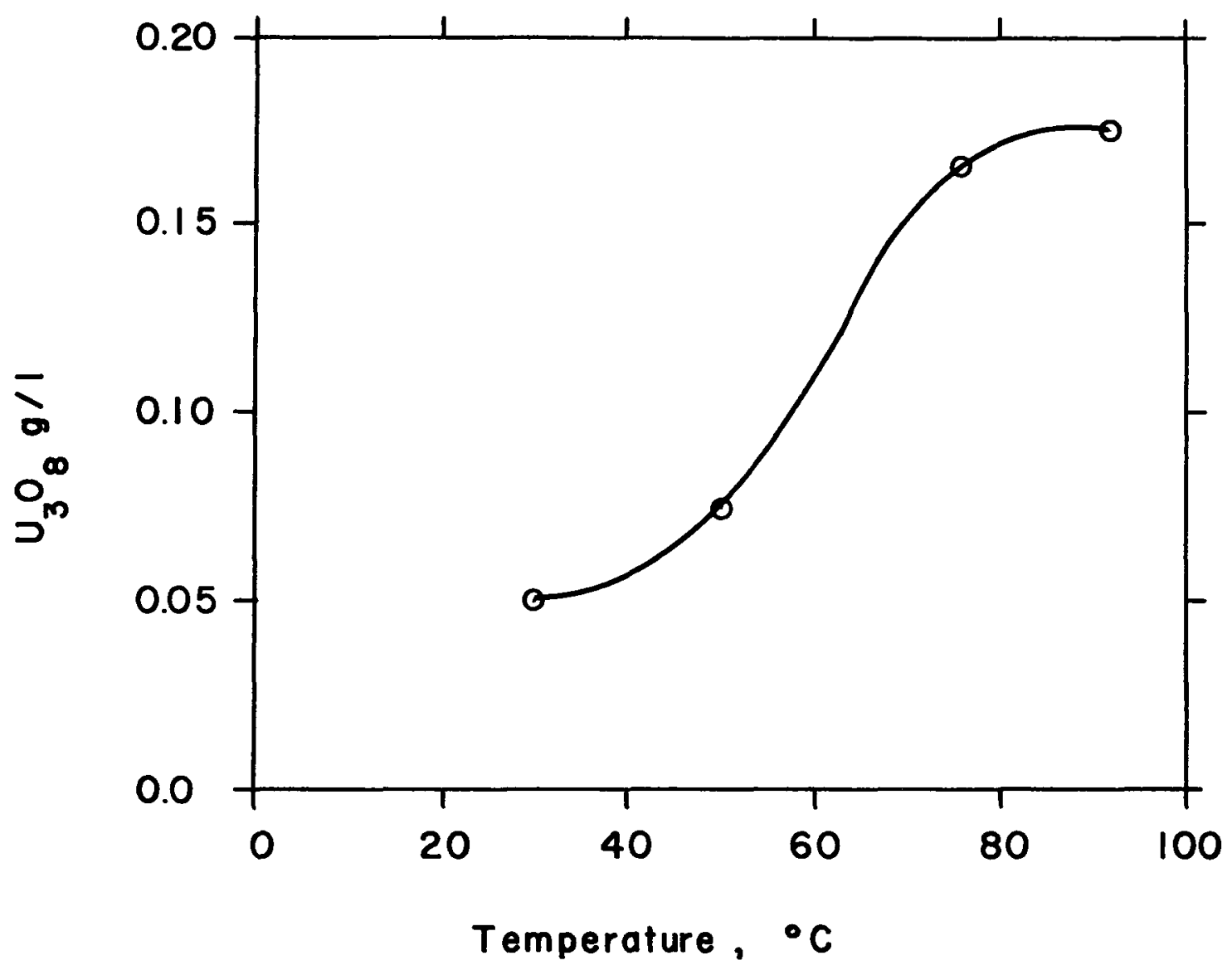

EFFECT OF TEMPERATURE ON THE SOLUBILITY OF UF 
WIN -90

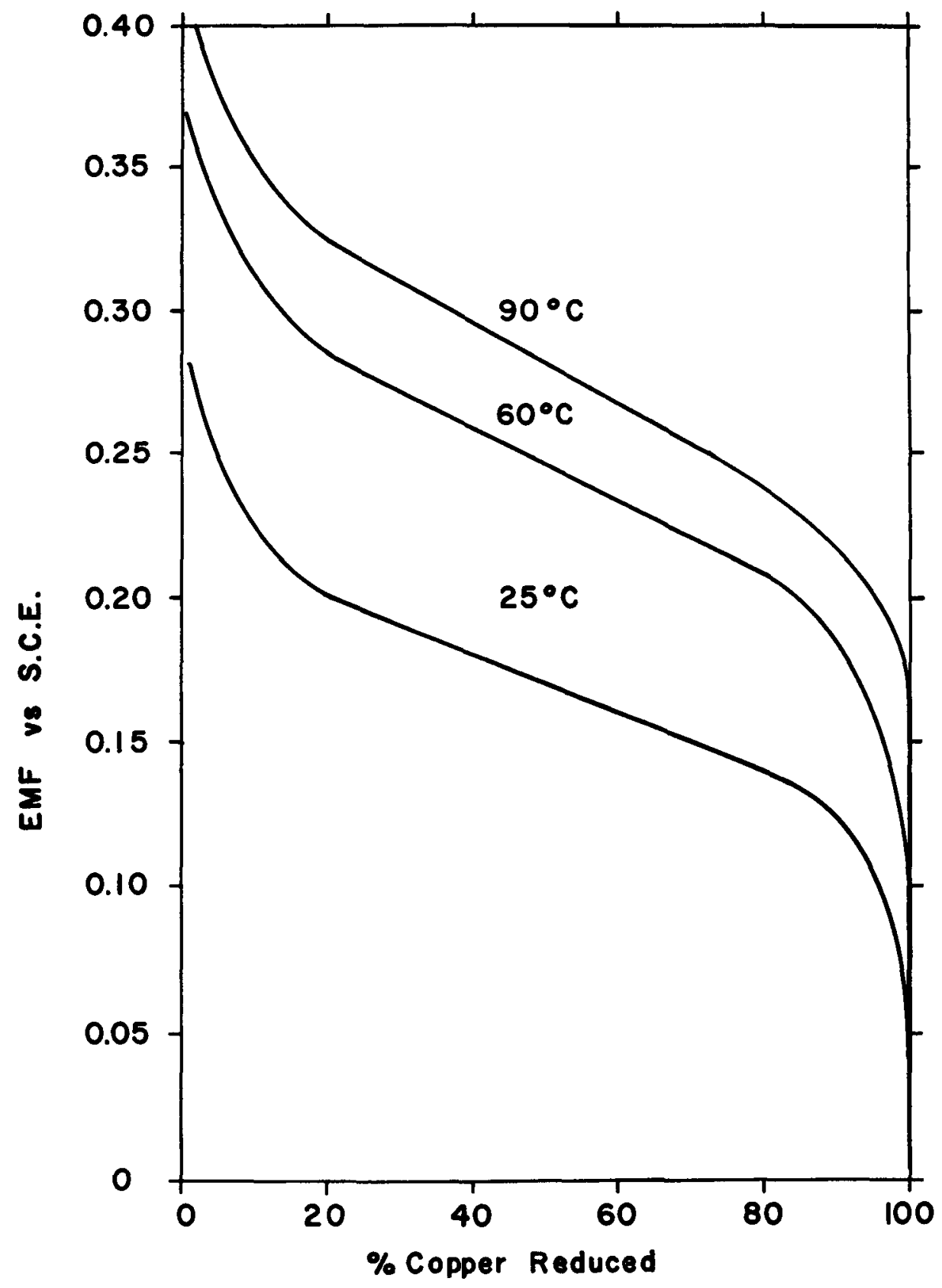

CHROMOUS REDUCTION OF CUPRIC COPPER 


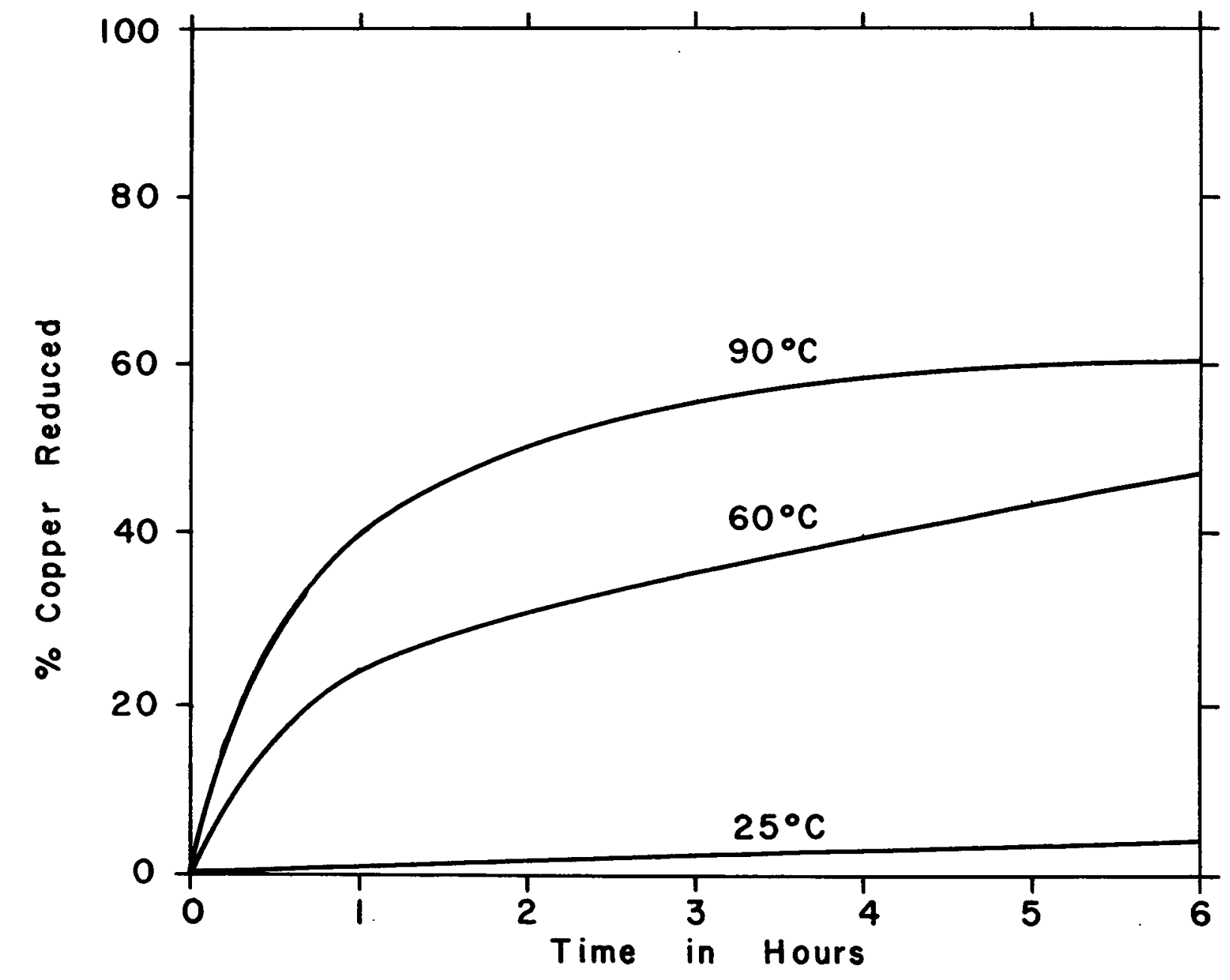

REDUCTION OF CUPRIC COPPER BY SULFUR DIOXIDE 


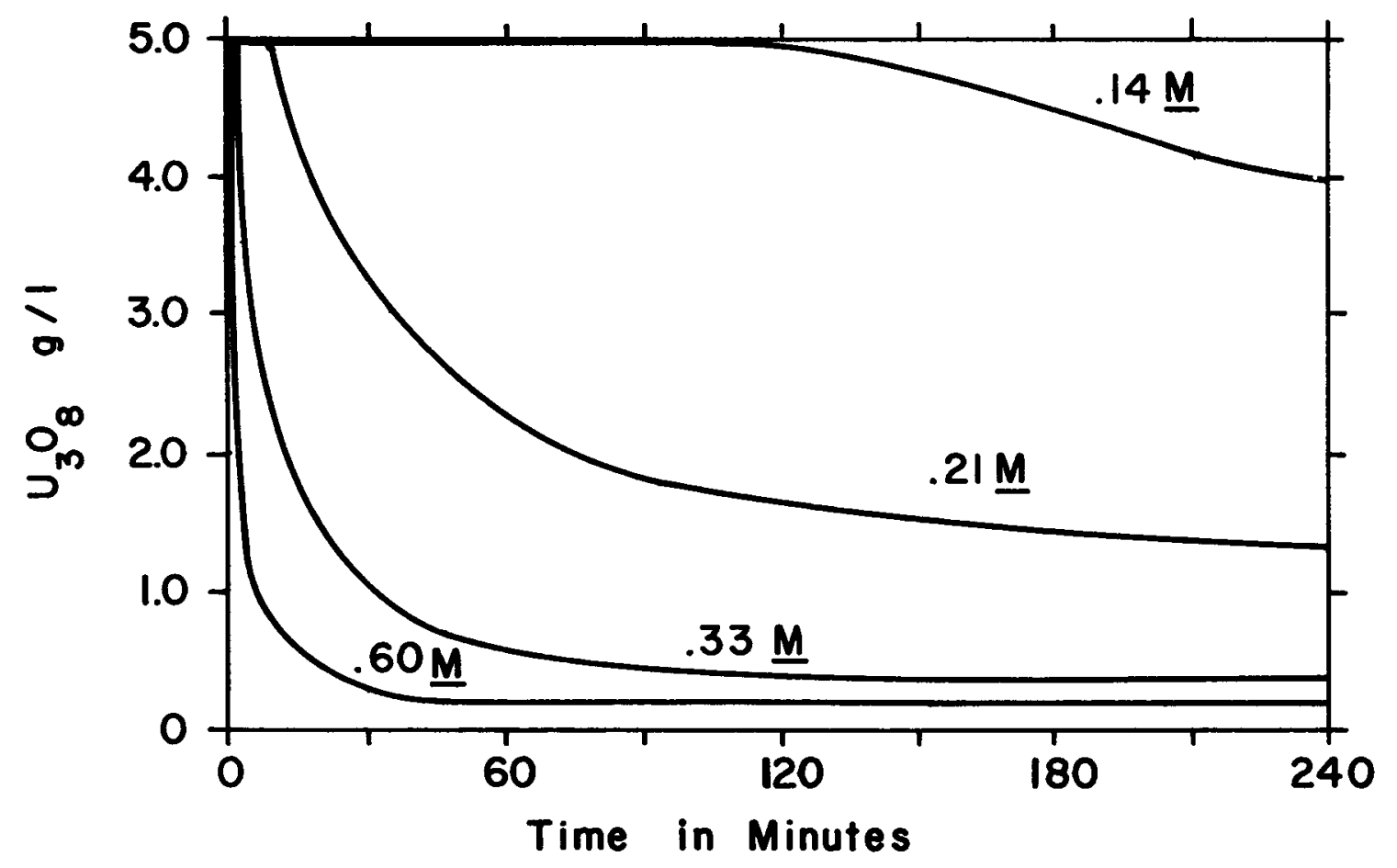

PRECIPITATION OF UF BY THE REDUCTION OF URANIUM BY CUPROUS COPPER IN THE PRESENCE OF FLUORIDE 